Portland State University

PDXScholar

1984

\title{
A theoretical and experimental examination of sodium chloride hydration
}

Debra Conway Modra

Portland State University

Follow this and additional works at: https://pdxscholar.library.pdx.edu/open_access_etds

Part of the Chemistry Commons

\section{Let us know how access to this document benefits you.}

\section{Recommended Citation}

Modra, Debra Conway, "A theoretical and experimental examination of sodium chloride hydration" (1984). Dissertations and Theses. Paper 3392.

https://doi.org/10.15760/etd.5278

This Thesis is brought to you for free and open access. It has been accepted for inclusion in Dissertations and Theses by an authorized administrator of PDXScholar. Please contact us if we can make this document more accessible: pdxscholar@pdx.edu. 
AN ABSTRACT OF THE THESIS OF Debra Conway Modra for the Master of Science in Chemistry presented February 23, 1984 .

Title: A Theoretical and Experimental Examination of Sodium Chloride Hydration

APPROVED BY MEMBERS OF THE THESIS COMMITTEE:

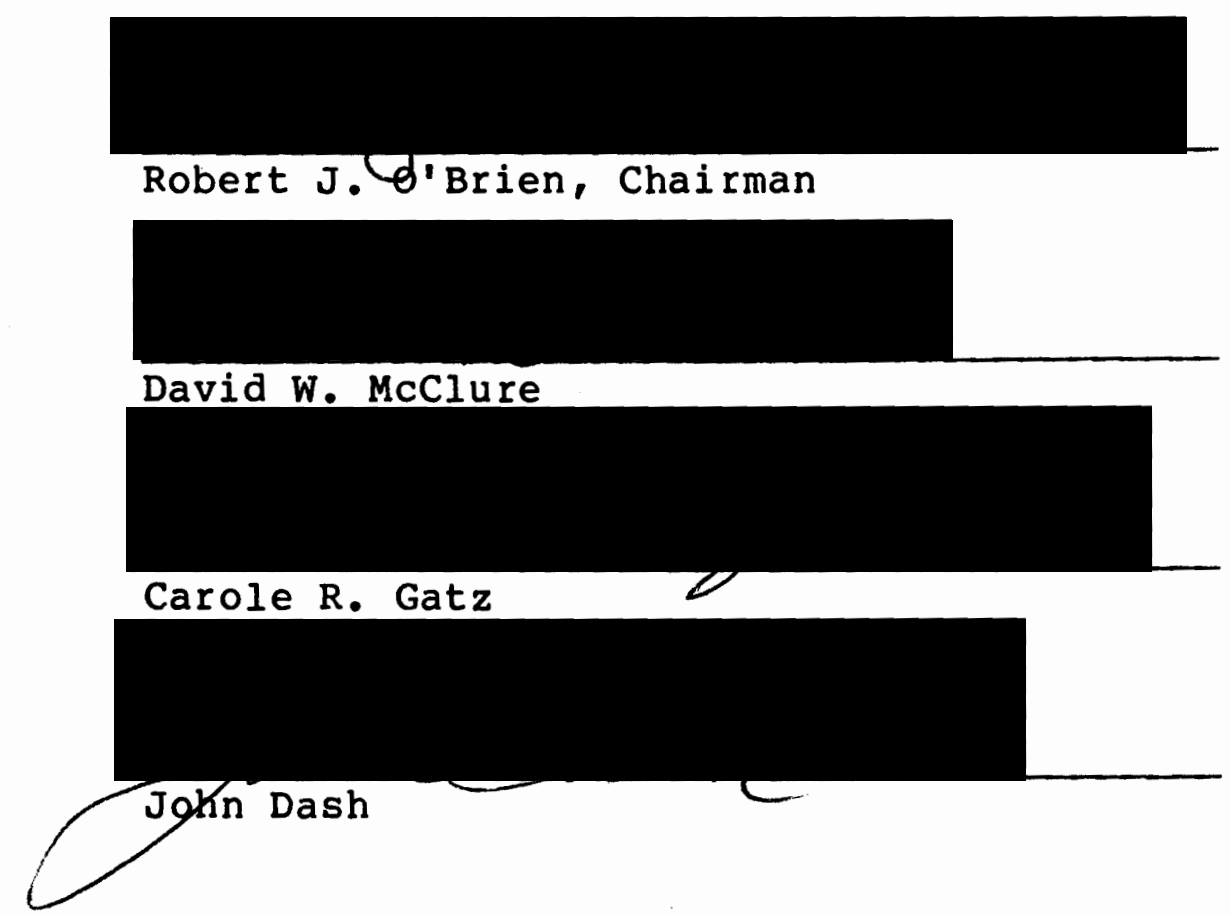

A Hitachi Hu $125 \mathrm{C}$ transmission electron microscope in which the standard specimen holder was replaced by an environmental cell was used to observe the hydration of sodium chloride crystals. To observe Kelvin curvature and solubility effects sodium chloride crystals which were $0.1 \mu$ or smaller were of special interest. An electrohome 
video system attached to the electron microscope was used to record the sodium chloride hydration for subsequent particle measurement and viewing.
A theoretical
was
also
developed. Thermodynamic properties such as the Kelvin curvature and solubility effects were considered as well as the kinetic expressions for salt dissolution/recrystalization and water evaporation/condensation. A computer program for use on a Honeywell computer was writtem to perform the required calculations.

The theoretical model was also used in attempts to explain the observed phenomenon of crystal shattering. 
A THEORETICAL AND EXPERIMENTAL EXAMINATION OF SODIUM CHLORIDE HYDRATION

$$
\text { by }
$$

DEBRA CONWAY MODRA

A thesis submitted in partial fulfillment of the requirements for the degree of

\author{
MASTER OF SCIENCE \\ in \\ CHEM ISTRY
}

Portland State University 
TO THE OFFICE OF GRADUATE STUDIES AND RESEARCH:

The members of the Committee approve the thesis of Debra Conway Modra presented February 23, 1984

Robert J Jo'Brien, Chairman

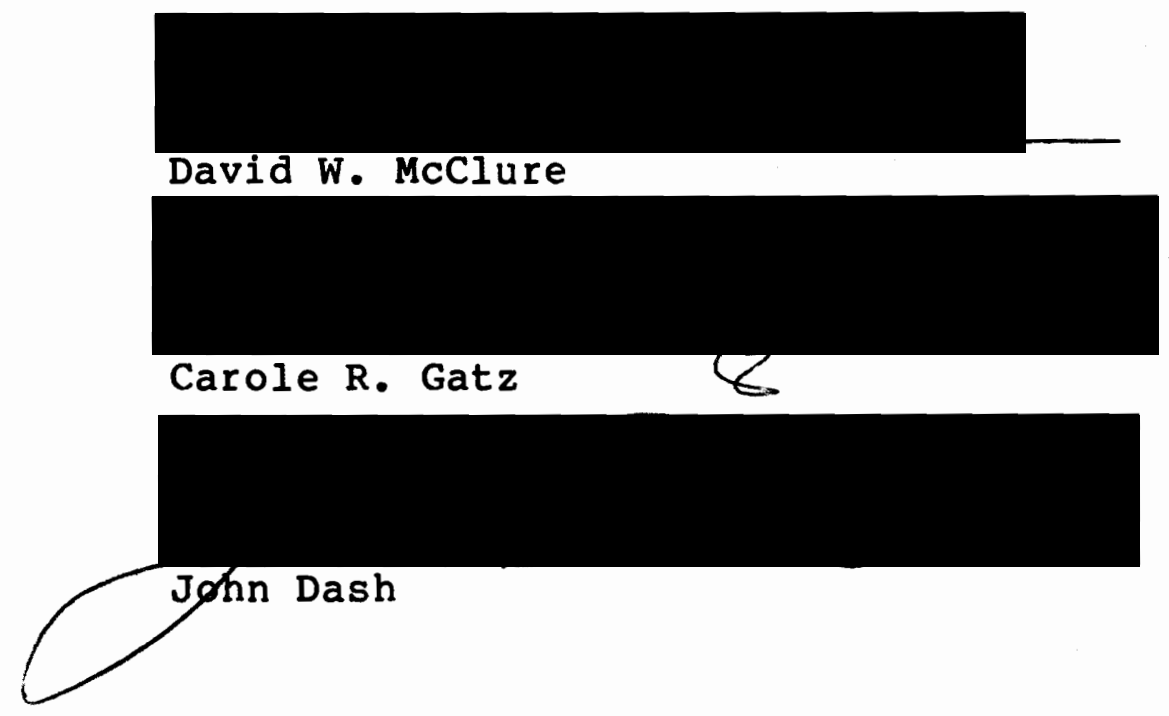

\section{APPROVED :}

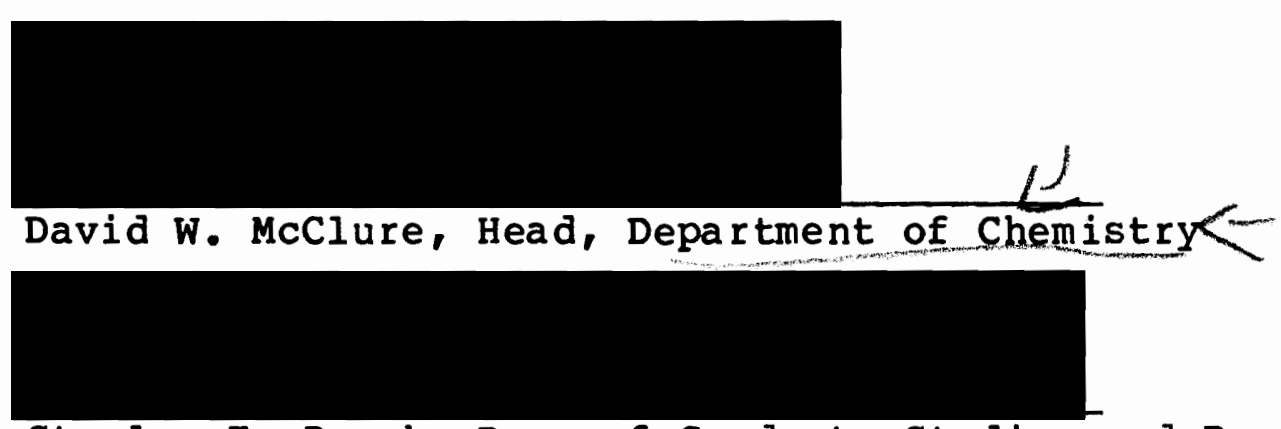

Stanley E. Rauch, Dean of Graduate Studies and Research 


\section{ACKNOWLEDGEMENTS}

The author would like to thank her advisor Dr. Robert J. O'Brien for sharing his knowledge with her. His guidance was essential to this, research.

Special thanks are also given to Dr. John Dash for operating the transmission electron microscope during the preparation for and the actual collection of these data.

Thanks are also extended to Antony Clarke and Larry Ternus who did the initial equipment assembly and testing, to the machine shop and electronics shop who helped with equipment modifications and repairs, and to Dr. Thomas Hard for equipment loans. 
TABLE OF CONTENTS

PAGE

ACKNOWLEDGEMENTS .................... ii

LIST OF TABLES..................... v

LIST OF FIGURES...................... vi

CHAPTER

I INTRODUCTION.................. I

II EXPERIMENTAL................. 8

III THEORY...................... 19

Thermodynamic............... 19

Kinetic................... 29

IV RESULTS AND DISCUSSION............ 45

v ConCLUSIONS................... 71

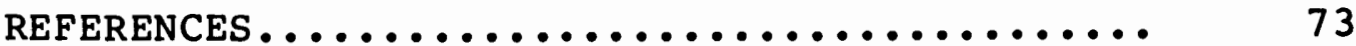

APPENDICES

APPENDIX A-Salt Impaction............ 78

APPENDIX B-Computer Model........... 83 


\section{LIST OF TABLES}

TABLE

PAGE

I Gas Phase Kinetics Equations.............. 36

II Experimental Data.................... 46

III Experimental Data................... 47

IV Experimental Data.................... 48

V Experimental Data-Trial 1................ 58

VI Experimental DAta-Trial 2.............. 59

VII Experimental Data-TRial 2 Dehydration........ 60

VIII Experimental Data-Trial 3............... 61

IX Experimental Data-Trial 3 Dehydration........ 62

X Experimental Data-Trial 4...............6 63

XI Computer Program for Integration for $\mathrm{NaCl}$

Hydration with Kelvin Considerations...... 84 
LIST OF FIGURES

FIGURES

PAGE

1. Environmental Cell..................... 9

2. Nebulizer and Cascade Impactor............. 10

3. Gas Handling System.................... 13

4. Kelvin Curvature vs Solute Effects.......... 27

5. NaCl Hydration Curves................... 28

6. Graphic Representation of Data in Table II.... 46

7. Graphic Representation of Data in Table III... 47

8. Graphic Representation of Data in Table IV.... 48

9. Computer Simulated Curves for Particle \#3

Table II after 5 seconds................ 51

10. Computer Simulated Hydration Curves

for the Particles in Figure 6............. 52

11. Computer Simulated Hydration Curves

for the Particles in Figure 7............. 54

12. Computer Simulated HYdration Curves

for the Particles in Figure $8 \ldots \ldots \ldots \ldots \ldots . . . .56$

13. Graphic Representation of Data in Table V.... 64

14. Graphic Representation of Data in Table VI.... 65

15. Graphic Representation of Data in Table VII... 66

16. Graphic Representation of Data in Table VIII.. 67 
vii

17. Graphic Representation of Data in Table IX.... 68

18. Graphic Representation of Data in Table X.... 69

19. Cascade Impactor Parts.................... 79 
CHAPTER I

\section{INTRODUCT ION}

The hydration properties of hygroscopic particles such as sodium chloride particles are an important part of the field of study known as cloud physics. The term cloud physics refers to the study of liguid and solid substances dispersed in the gaseous media known as the atmosphere. The hydration properties of hygroscopic particles are of particular importance in understanding fog, haze and cloud formation (and in the area of weather control, particularly concerning artificial fog dissemination). The hydration properties of hygroscopic particles have also become important in the health field concerning the deposition of particles in the respiratory tract.

Since the late $1800^{\prime}$ 's it has been known that condensation nuclei are necessary for the formation of fog, haze and clouds. Twomey and McMaster (1) cite sea-salt particles in the atmosphere as one possible source of condensation nuclei. Fog, haze and clouds result from the condensation of water on these nuclei. The term fog generally refers to this condensation process occurring at the earth's surface whereas clouds usually form higher 
in the atmosphere and are generally associated with the adiabatic cooling of large air masses as they ascend over mountains or colder air. If the air at the earth's surface cools below its dew point and the condensation of water on the existing nuclei reduces the visibility to a range of one kilometer or less fog is said to exist. Two common situations in which fog occurs are (I) when warm damp air moves into an area where the ground is cold and (II) when the ground is cooled by radiant heat loss to a clear sky at night. The term haze is a less precisely defined term and refers generally to very small solid or liquid particles dispersed in the atmosphere. Mie scattering from these small particles generally results in haze having a characteristic blue color. The hygroscopic nature of atmospheric particulates and their hydration properties also affect the general moisture content in the atmosphere with ramifications in such atmospheric phenomena as the green house effect.

One of the earliest workers to consider the equilibrium size of droplets with dissolved or dissolving hygroscopic particles as a function of relative humidity was Koehler (2) in 1936. Koehler considered both the lowering of vapor pressure over the droplet due to dissolved solute and the increase of vapor pressure over the droplet due to the Kelvin effect. The Kelvin effect was used and accepted because of the accuracy of 
predictions which were based on the Kelvin equation though it was not until 1951 that LaMer and Gruen (3) gave experimental evidence for the validity of the Kelvin equation. Koehler, however, used Raoult's law to predict the vapor pressure lowering effect of the dissolved solute. This limited the applicability of the Koehler equation to the region of high dilution and therefore high relative humidities. Other earlier experiments such as those by Dessens (4) and Howell (5) also used the Raoult's Law approximation for vapor pressure lowering of the solute. Keith and Arons (6) and Twomey (7) also addressed the question of the growth rate of hygroscopic particles. However, their studies dealt with particles which were too large to illustrate Kelvin curvature effects. Since particles with a radius of less than $0.1 \mu$, known as Aitken nuclei, are the size range of particles of the greatest concentration in the atmospheric aerosols, more current investigations such as those by Orr, Hurd and Corbett (8) and Dennis (9) have dealt with particles down to this size range. Orr, Hurd and Corbett (8) developed theoretical growth curves which include both hygroscopic and deliguescent growth.

In this thesis the terms deliquescent and hygroscopic shall be used according to the definition given by Covert, Charlson and Ahlquist (10):

Deliquescent refers to the property of certain 
compounds, primarily inorganic, water-soluble salts to form a solution when the solid compound is exposed to water vapor in an atmosphere having a partial vapor pressure greater than that of the saturated solution of its highest hydrate. Hygroscopic refers more generally to the property of a larger class of compounds to adsorb or absorb water vapor over a wide range of partial pressures by a variety of physical and/or chemical mechanisms.

The major difference of these two classes of compounds in reference to growth rate observations was noted by Tang (11).

The growth curves displayed by these two classes of materials are quite different in shape. While deliquescent salts show distinctly the onset of growth, a hygroscopic particle grows continuously and smoothly with increasing humidity

An understanding of the hydration properties of hygroscopic particles is of importance not only in understanding the formation of fog but also in dealing with the visibility problems created by fog. It is known that maritime air masses, which contain sodium chloride picked up by winds blowing over bodies of salt water, have reduced visibility on humid days (12). Furthermore, sodium chloride's effect on visibility with changing relative humidity serves as a fairly accurate predictor of visibility in maritime air with changing relative humidity (13). Thus, an accurate understanding of the hydration properties of sodium chloride would increase the understanding of visibility problems caused by fog. An understanding of the properties of hygroscopic particles 
at various relative humidities is also essential in the artificial dissipation of fog using hygroscopic particles. Two main methods are used for artificial dissipation of fog : (I) evaporation of fog droplets by heat or (II) evaporation of fog droplets by hygroscopic substances (usually calcium chloride or ammonium nitrate crystals in the millimeter size range). The hygroscopic particles sprayed into fog are meant to absorb enough water to reduce the relative humidity of the air below the level at which condensation occurs on the nuclei which are present in the atmosphere thus leading to evaporation of water from the fog droplets to the falling hygroscopic particles. An understanding of dehydration hysteresis is also important in understanding why fog lingers even below the relative humidity at which it was formed.

It is known that the health hazard of atmospheric particulates is directly related to their being deposited deep in the respiratory tract and in the lungs. According to Brown et.al. (14) the human respiratory tract does selectively eliminate particulates based on the particulates aerodynamic properties. Thus, the properties of the particulate determine the extent of lung penetration and the likelihood of the particulate to cause respiratory disease. Since the human respiratory tract is quite moist, hygroscopic particles can hydrate causing a size increase. The effect of this change in size as a 
particle moves down the respiratory tract, or in other words the hydration properties of hygroscopic particles at the temperature and relative humidity of the human respiratory tract (in reference to lung penetration) has been dealt with by Held and Cooper (15).

Thus, it can be seen that there is a fairly broad base of interest in the hydration properties of hygroscopic particles: from the effect of these particulates on weather conditions such as clouds, fog and haze and the elimination of the visibility problems caused by fog to the health hazards of these hygroscopic particles. But, in spite of the broad base of interest in the hydration of hygroscopic particles and the amount of time and effort applied to the problem, disagreement still exists concerning the effect of relative humidity on sodium chloride particles. In particular, the hydration curves for sodium chloride particles of various diameter with relative humidity as given by Cinkotai (16) do not agree with those given by Orr, Hurd and Corbett (8). One reason for the discrepancy in these curves is the failure of Cinkotai to consider the increased solubility of small soluble particles due to surface curvature effects.

The purpose of this experimentation is to observe the hydration of sodium chloride crystals and derive a theoretical expression which predicts the growth rate of these crystals. Special emphasis was placed on observing 
crystals in the size range where the Kelvin effect and increased solubility due to surface curvature effects were apparent: particles less than approximately $0.1 \mu$ in diameter, though larger particles were also observed. This is also the particle size range which would be of practicle importance since the greatest concentration of atmospheric aerosols are Aitkin nuclei (particles with radii less that $0.1 \mu$ ). Sodium chloride was chosen for these experiments not only because it is a major component in maritime air particulates but also because it illustrates deliquescent behavior. Though several atmosphertc particulates are mixed salts, an understanding of the hydration of sodium chloride crystals can serve as a basis for understanding these systems.

To attain this goal a transmission electron microscope fitted with an environmental cell based on the principles outlined by Chang and Parsons (17) was used. At least in reference to fog droplet size distributions a microscopic method is the method of choice (18). Furthermore, a microscopic method allows visual observation of the actual hydration process and since an electron microscope operates under vacuum the possibility of erroneous hydration values due to the effects of unwanted gases as described by Keng (19) is reduced. 


\section{CHAPTER II}

\section{EXPERIMENTAL}

The hydration of sodium chloride crystals took place in a Hitachi Hu 125 C transmission electron microscope in which the standard specimen holder was replaced by an environmental cell designed and manufactured by the Ernest F. Fullam Co. (Fig. 1). Sodium chloride particles were deposited on the environmental cell's $2.3 \mathrm{~mm} 400$ mesh wet cell windows, henceforth known as grids, using a DeVilbiss nebulizer and Anderson-type cascade impactor (Fig. 2) according to the procedure outlined in Appendix A. To improve the accuracy of droplet size measurements a dilute solution of dow latex particles (for size calibration) were deposited on the grid along with the salt particles. The manufacturer of the latex particles states that these particles were $0.091 \mu$ in diameter with a standard deviation of $0.0058 \mu$ (206 measurements).

Once the grids were prepared, the environmental cell was held inverted over a pen light bulb with a reflective lens powered by a six volt battery (with a clamp on a ringstand). The cell was clamped in a position such that light shone up through the hole for the electron beam from 


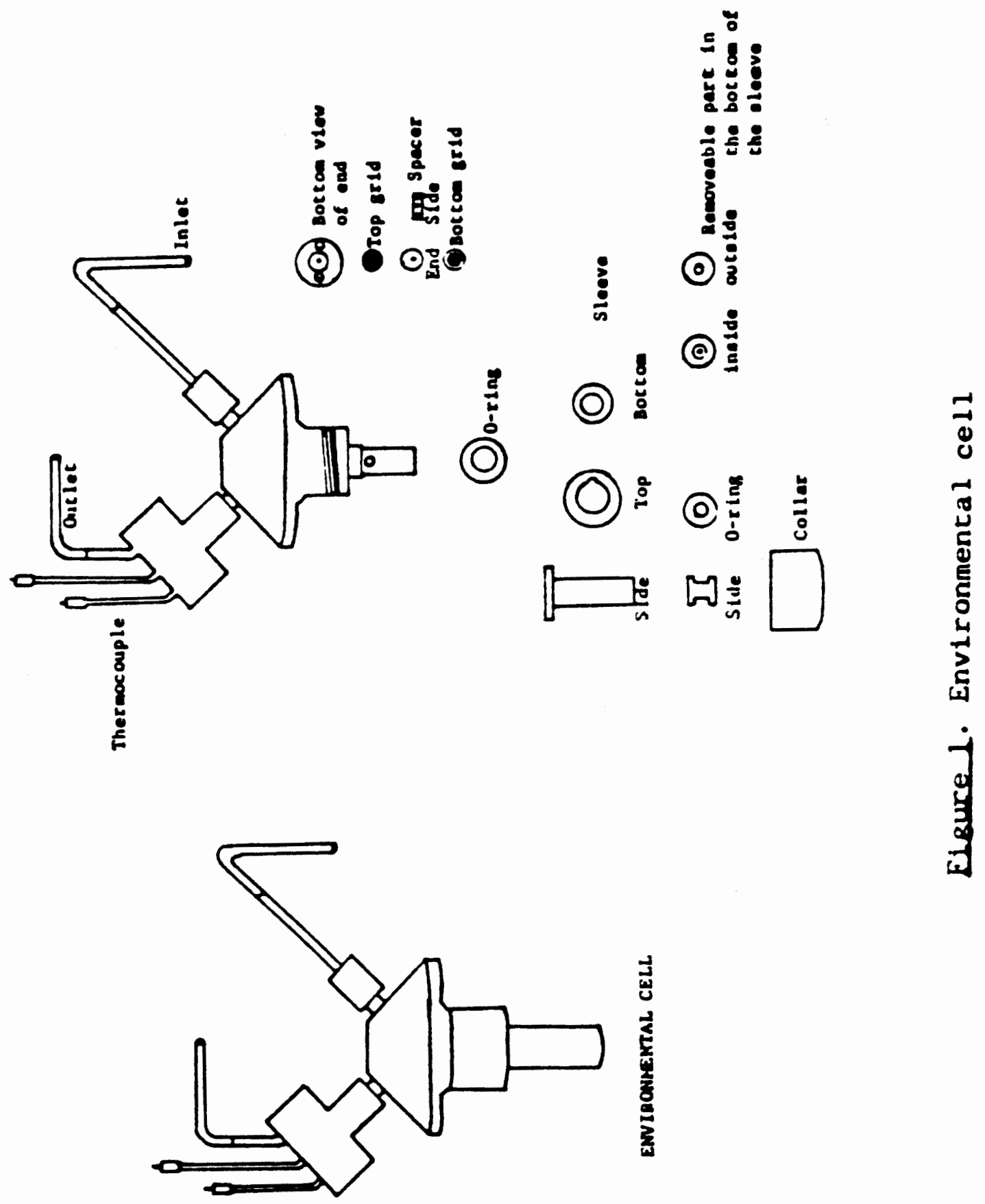




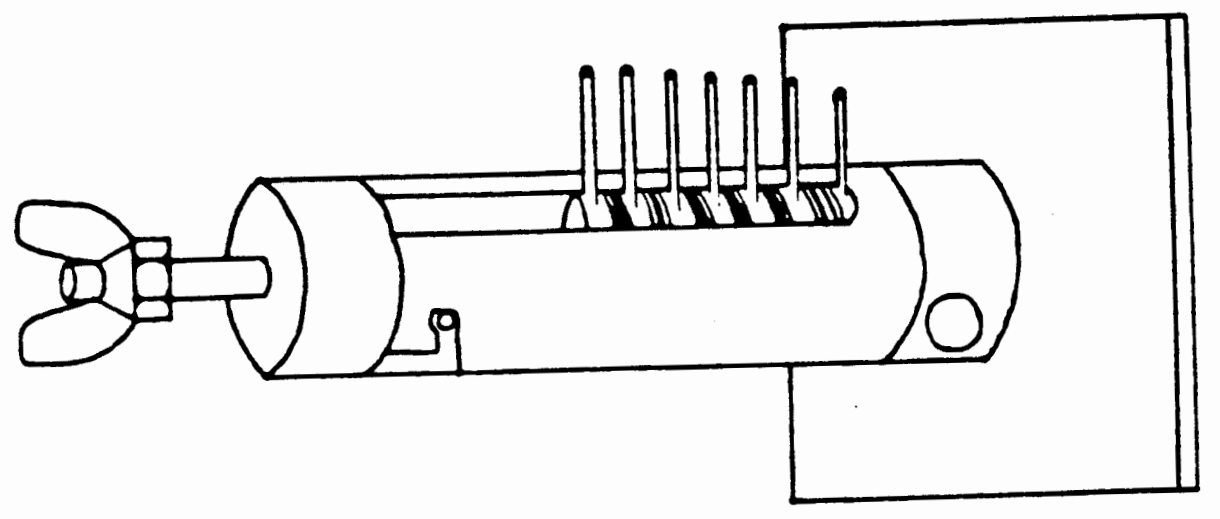

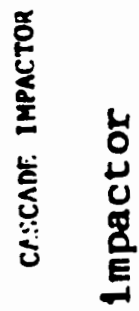

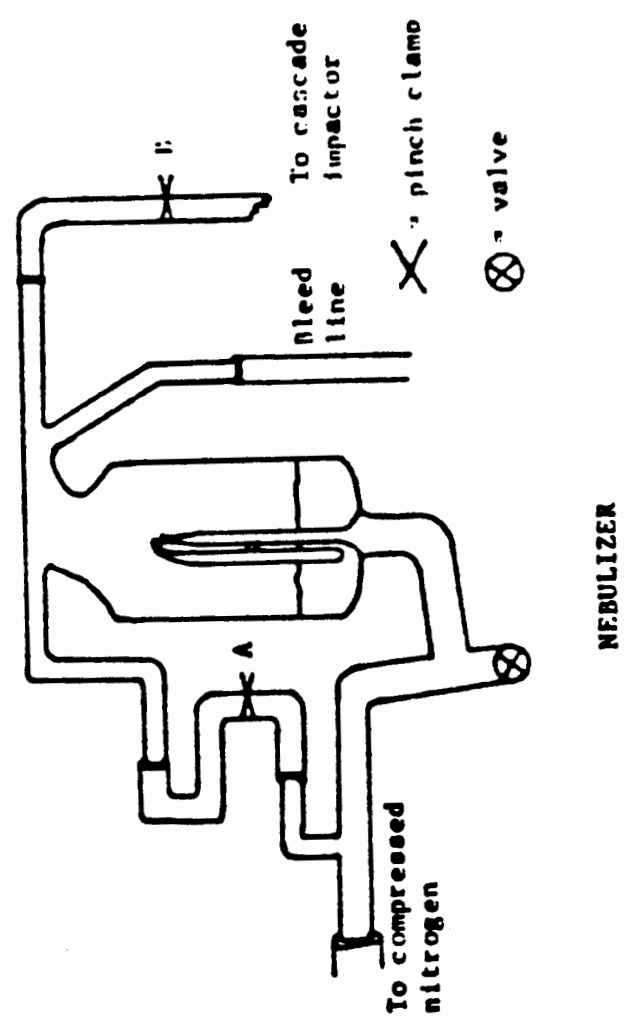


the gas inlet, gas outlet side of the cell. In this inverted position the compression spacer was facing upward when the collar and sleeve were removed. A new unused grid was placed in the top grid position, below the compression spacer, with the shiny side of the grid facing upward. A level was then used to assure that the cell and thus the grid were parallel to the light microscope which was used to align the upper and lower grids. When the environmental cell was adjusted to a parallel position, the compression spacer was inserted and the grid with salt particles on it was placed on the compression spacer with the shiny side down (shiny side facing the compression spacer). This grid was then adjusted so that the upper and lower grids were aligned. Alignment of the grids was necessary to permit unobstructed or deflected passage of the electron beam. When alignment was achieved the sleeve and collar were replaced. The collar was turned until finger tight to assure a proper seal. The environmental cell was now vacuum tight with the coating on the grids providing the seal from leakage of gas through the electron beam hole while the o-rings prevented leakage of gas from the cell itself.

A copper-constantan thermocouple was installed in the outlet tube of the environmental cell to allow the temperature of the chamber to be read. The output voltage from the thermocouple was read on a Heathly voltmeter set 
on the millivolt range. The thermocouple was calibrated against the ice point of water, the melting point of acetic acid and t-butyl alcohol, and water at various temperatures, using a thermometer calibrated to 0.02 degrees centigrade for a temperature range of 19 to 35 degrees centigrade.

The gas delivery apparatus (Fig. 3) had both an oil and a mercury manometer. During actual operation only the oil manometer was in use. It was used to determine the approximate water vapor pressure delivered to the delivery piston. Convoil-20, purified hydrocarbons, was the oil used in the oil manometer. The density of the oil in this oil manometer was determined by weighing one ml. samples of the oil using an analytical balance and calibrated pipet. The density of the oil was found to be $0.85 \mathrm{~g} / \mathrm{ml}$. The mercury manometer was used only to check the efficiency of the mechanical pump.

During the initial stages of apparatus assembly a $C$. J. Enterprises model CJ3D variable reluctance pressure transducer was used. Output voltages of this guage were read on a Fluke voltmeter. Because of the position of the attachments, this guage could be used to read pressure drops across the environmental cell, the inlet pressure referenced against the the mechanical pump vacuum, or the outlet pressure referenced against the the mechanical pump vacuum. The final position was attachment of both sides of 


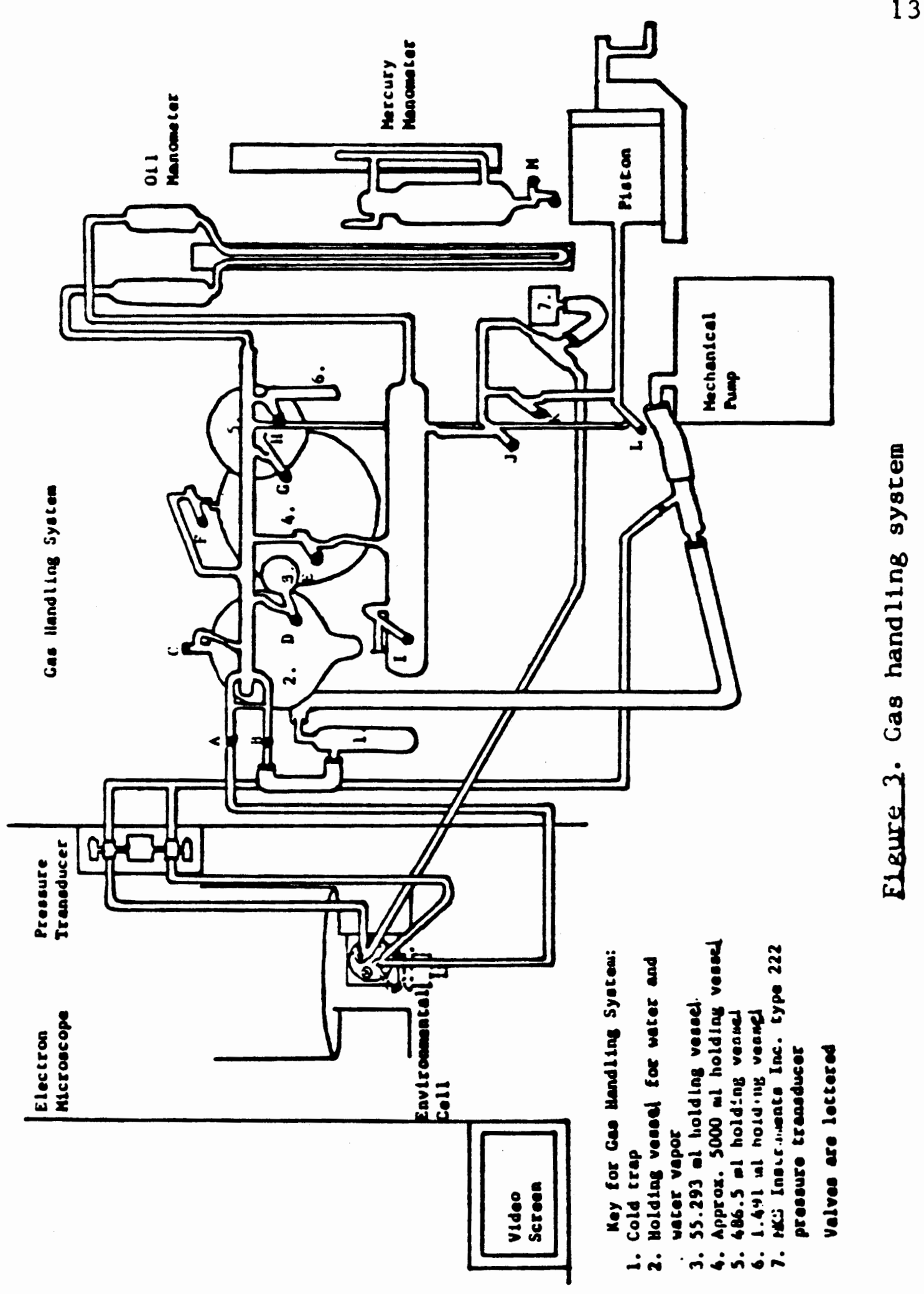


the transducer to the the mechanical pump vacuum. This position prevented damage to the pressure gauge diaphram during large pressure changes in the other parts of the system. The pressure gauge was calibrated against an oil manometer prior to installation.

Due to repeated inconsistencies in the C.J. Enterprises model CJ3D variable reluctance pressure transducer, in spite of replacement of the pressure diaphram and servicing of the power supply by the manufacturer, an MKS Instruments Inc. type 222 pressure transducer was used during actual data collection. This gauge was an absolute pressure gauge and was used to read the inlet water vapor pressure. The gauge was factory calibrated to be linear in the 0 to 100 torr range with a maximum voltage output of $10 \mathrm{~V}$ at the maximum readable pressure of 100 tor $r$. The linearity of the pressure gauge was checked using the oil manometer on the gas delivery system •

The pressure of water vapor delivered to the environmental cell was regulated by a cylinderical piston. The volume of the cylinder and thus the pressure of the water vapor it held could be changed by an attached variable speed motor, or by manually cranking the piston.

The sealed environmental cell was placed in the microscope column by removing the liquid nitrogen trap. Valve P, (Fig. 3) which opened the microscope column to 
the environmental cell, was then opened and the microscope was pumped down. This valve must be in the open position while the microscope is either being pumped down or being brought up to atmospheric pressure to prevent a large pressure differential across the grid membrane with resultant damage to the membrane. The gas delivery system was pumped down by opening valve $B$, thus opening the gas delivery system to the mechanical pump. Valves 0 and $N$ open the respective right and left arms of the oil manometer to the pump when valve $\mathrm{E}$ is open. During water vapor delivery, the water vapor pressure is measured by closing valves $E, I$ and $J$ with valve $O$ opened while the system is in an evacuated state and using the right arm of the oil manometer as the reference side. When valve $C$ is opened water vapors in holding vessel 2 enter the evacuated line. It is essential that valves $A, K$, and $E$ or $J$ are closed to prevent leakage of the water vapor into the environmental cell before actual water vapor delivery is desired. Valve $B$ must also be closed to prevent The water vapor from simply being pumped away by the mechanical pump. With valve $L$ opened the water vapor enters the delivery piston. After a short equilibration period with valve $\mathrm{N}$ open the oil manometer reads the pressure of water vapor in the delivery piston. Generally when the delivery piston was charged with water vapor in this manner the piston was in its most open (largest 
volume) position. When the desired pressure of water vapor had been delivered to the delivery piston valves $C, L$, and $K$ were closed and the gas delivery system was again evacuated.

The connections between the gas handling system and the environmental cell were made with tygon tubing. Metal inserts were used in the tygon tubing at swagelock fittings to assure vacuum tight seals without constriction of the tubing. A flow valve, which could regulate the flow of water vapor through the environmental cell, located in the outlet tubing, was left in a fully open position since no pressure drop across the cell occured even in the full open position.

The water vapor in the delivery piston was delivered to the environmental cell by first closing valve $P$ to prevent leakage of the water vapor into the microscope column, opening valve $A$ to allow the inlet gas to flow to the outlet and be collected in the liquid nitrogen trap, and then opening valve $k$. Since the inlet vapor was continually pumped away at a slow rate by the mechanical pump the piston must be closed at a very slow rate to maintain a constant pressure and at a slightly faster rate to increase the water vapor pressure delivered to the salt particles in the environmental cell. The delivery piston does have a variable speed motor drive but it was found that better control was attainable by 
manually cranking the piston. Cranking counter clockwise opened (increased the volume of) the piston and cranking clockwise closed (decreased the volume of) the piston. It can be shown that the change in water vapor pressure in the delivery piston is related to the change in the length of the cylindrical delivery piston (as altered by turning the crank as described above) in a geometric fashion:

Assuming an ideal gas laws

$$
\begin{aligned}
& P V=n R T \\
& V=\pi r^{2} 1 \\
& P\left(\pi r^{2} 1\right)=n R T \\
& P=\frac{n R T}{\pi r^{2} I} \\
& d P=-\frac{n R T}{\pi r^{2} I^{2}} d 1
\end{aligned}
$$

$$
\begin{aligned}
& \mathrm{P}=\mathrm{H}_{2} \mathrm{O} \text { vapor pressure } \\
& \mathrm{V}=\text { volume of the delivery } \\
& \text { piston which is cylindrical } \\
& \text { in shape } \\
& \text { n=number of moles of } \mathrm{H}_{2} \mathrm{O} \\
& \text { vapor } \\
& \mathrm{R}=\text { Gas Law constant } \\
& \mathrm{T}=\text { temperature (assumed } \\
& \text { constant) } \\
& \mathrm{l}=\text { lenght of the cylinder } \\
& r=\text { radius of the cylinder }
\end{aligned}
$$

One further consideration in the gas delivery process is that if the temperature inside the environmental cell chamber is higher than the temperature inside the delivery piston gas may not be delivered to the cell. This is a result of the fact that at higher 
temperatures the gas has a higher pressure and the water vapor will not flow to a region of higher pressure. If enough pressure is applied to the water vapor in the piston the water vapor will simply condense in the cylinder. This situation can occur if the salt particles have been exposed to the electron beam for an extended period of time.

The salt particles in the environmental cell can be observed on the electrohome video system attached to the electron microscope. The image on the electrohome video receiver was also recorded on video tape as a record of the hydration for subsequent droplet size measurements. The video screen was split so that the digital readout from the thermocouple, a timer, and the digital readout from the pressure transducer voltmeter were recorded across the top to the video screen. The data was obtained from diameter measurements off the electrohome video screen upon replay of the video tape. The time resolution of the video tape was one frame every sixtieth of a second. The tape was manually turned from frame to frame to obtain droplet diameters every sixtieth of a second. 


\section{CHAPTER III}

\section{THEORY}

\section{THERMODYNAMICS}

Using the previously described apparatus, the electron microscope and salt particles were evacuated to the operating pressure of $10^{-4}$ to $10^{-5}$ torr. Thus, it is reasonable to assume that substances adsorbed to the surface of the sodium chloride crystal had been removed. This, however, leaves unsatisfied molecular forces in the surface layers of the sodium chloride crystal. Thus, when water vapor is introduced, physical adsorbtion of the water takes place to satisfy molecular forces associated with the surface layers of the crystal. Therefore, the first physical changes in these supposedly pure sodium chloride crystals occurs at those relative humidities below that required for hydration. the adsorbtion isotherm may be described by using the Brunauer, Emmett, Teller (20) equation for the adsorption of gases in multimolecular layers:

$$
V=\frac{V_{m} C P}{\left(P_{0}-P\right)\left(1+(C-1)\left(P / P_{0}\right)\right)}
$$


$V_{m}=v o l u m e$ of adsorbed gas required to cover the entire adsorbing surface with a unimolecular film

$V=$ volume of gas adsorbed at pressure $P$

$P_{0}=$ vapor pressure of the adsorbing gas at the experimental temperature $\mathrm{I}$

$C=a$ constant $B_{1}$ ven by $C=\frac{a_{1}-b_{2}}{b_{1}} a_{2} e^{\left(E_{1}-E_{L}\right) / R T}$

where $a_{1}, a_{2}, b_{1}$, and $b_{2}$ are constants

$E_{1}$ heat of adsorption of gas in the first layer

$E_{L}=$ heat of liquifaction of the gas

$R=t$ he gas constant

$\mathrm{T}=$ the absolute temperature $\left(O_{\mathrm{K}}\right)$

This was the approach taken by Orr, Hurd and Corbett (8) who used a sodium chloride surface energy value of 276 ergs/ $\mathrm{cm}^{2}$, a value of $10.8 \AA^{2}$ for the surface area covered by a single water molecule and the approximations that the quantity $E_{1}-E_{L}$ (the energy of addition of the first layer of adsorbed water minus the energy of water vapor liquifaction) is equal to the surface energy of sodium chloride and that the constants $a_{1}, a_{2}, b_{1}$, and $b_{2}$ were such that $a_{1} b_{2} / b_{1} a_{2}$ is approximately unity and thus $C=e^{\left(E_{1}-E_{L}\right) / R T}$. Carrying out the calculation for the energy in calories per mole of water molecules represented by the sodium chloride surface energy of $276 \mathrm{erg} / \mathrm{cm}^{2}$ and then evaluating $C$, a value of approximately 1392 is obtained for C at 298.17 degrees Kelvin. Though this seems to be a reasonable value for $c$, two approximations were made to 
obtain this value. Thus, since empirical data was available for the absorption of water vapor on sodium chloride crystals at $25^{\circ} \mathrm{C}$ (21) it was decided to use the empirical data when description of the adsorption isotherm or when precise initial condition calculations were desired. At water vapor pressures below hydration pressure the sodium chloride crystals may be thought of as cubic crystals with one or more layers, depending upon the water vapor pressure, of water adsorbed to its surface. According to Barraclough and Hall (21), "It has been noted that after the absorption of the first two water layers on $\mathrm{NaCl}$, the system behaved as if a saturated solution of NaCl were present." Thus, after the adsorption of the first two water layers the adsorbed water acts as a solvent and dissolves the sodium chloride crystal to some extent. The amount of sodium chloride which dissolves to make a saturated solution of the adsorbed water generally causes a negligible change in the length of the salt cube for large salt particles but may be significant for extremely small salt particles.

As the vapor pressure approaches the pressure of hydration the salt cube becomes a crystalline cube with saturated sodium chloride solution adsorbed to it. The water vapor pressure above the salt cube is then the vapor pressure of a saturated sodium chloride solution. This vapor pressure of bulk $\mathrm{NaCl}$ with more than two layers of 
water adsorbed is given by $\mathrm{Pl}=\mathrm{a}(\mathrm{PO})$ where $\mathrm{Pl}$ =the water vapor pressure above the saturated salt solution, a=the activity of water in a saturated salt solution and $P 0=$ the vapor pressure of pure water at the experimental temperature. At an ambient vapor pressure greater than Pl, hydration occurs. Since the salt cube is sitting on the grid surface the water added to the salt cube forms a spherical cap around the cube rather than a droplet as would be formed if the salt particle was not sitting on a surface. Spherical cap formation and growth is thus indicative of hydration. Two other factors, however, influence the vapor presssure above the sodium chloride crystal: (I) The vapor pressure of films with very great curvature is increased according to the Kelvin equation and (II) Small particles are more soluable than large particles (again the result of Kelvin effects) (22) or, in other words, small particles are in equilibrium with higher concentrations of solution than are larger particles. This results in a vapor pressure lowering over very small particles according to Raoult's Law.

The vapor pressure increase due to surface curvature of the film is given by the Kelvin equation:

$$
\ln \left(\frac{P}{P O}\right)=\frac{2 M \gamma}{\operatorname{RTE} r}
$$


$P=$ vapor pressure over the curved surface of radius $r$ $\mathrm{PO}^{\circ}=$ vapor pressure of a solution of infinite extent $M=$ molecular weight of the solvent $\gamma=$ surface tension of the solution $e=s o l u t i o n$ density $r=d r o p l e t$ radius

$R=g a s$ constant

T=absolute temperature

This thermodynamic relationship between surface curvature and molar free energy may be derived from the combined statement of the first and second laws of thermodynamics, the Gibbs free energy, the Young and Laplace equation and the ideal gas law. The combined statement of the first and second laws of thermodynamics is $d E=T d S-P d V-d w_{r e v}^{\prime}$ where $E=$ internal energy; $T$ =absolute temperature; $S=e n t r o p y$; $\mathrm{P}=$ external pressure; $\mathrm{V}=\mathrm{vol}$ ume and $d w_{\mathrm{rev}}^{\prime}=\mathrm{all}$ work other than pressure-volume work. But $G=H-T S$ where $G=G i b b s$ free energy and $H=e n t h a l p y$ as defined by the alternative statement of the first law of thermodynamics $H=E+P^{\prime} V$ where $P^{\prime}=$ pressure of the system. Using Euler's Theorum these expressions may be quickly differentiated: $d G=d H-T d S-S d T$ and $d H=d E+P d V+V d P$. Therefore, $d G-d E=P d V+v d P-T d S-S d T$ or using the combined first and second laws of thermodynamics $d G=V d P-S d T-d w_{r e v}^{\prime}$ since in this case there is no provision for the system to do any work except pressure-volume work 
$d w_{r e v}^{\prime}=0$ and $d G=V d P-S d T$. Furthermore, if isothermal conditions are applied $d G=V d P$ or upon integraton $\Delta G=\int v d P$. This integrated equation applies to reversible changes in pressure under conditions such that $d w=0$ and $T=$ constant. These are precisely the conditions which exist when discussing the equilibrium vapor pressure over a curved surface since at equilibrium the molar free energy of the condensed phase must be the same as that of the vapor phase to satisfy the free energy criterion for equilibrium. If this equilibrium criterion is not met spontaneous evaporation or condensation occurs. Considering the molar volume $\mathrm{V}$ to be constant and using the Young and Laplace equation which gives the pressure difference across a curved surface (fundamental equation of capillarity $): \Delta P=\gamma((1 / R I)+(1 / R 2))$ where $\gamma=$ the surface tension and $R 1$ and $R 2$ are the radii of curvature, which are equal for a sphere, the equation $\Delta G=\gamma V((1 / R 1)+(1 / R 2))$ results. Or, for a spherical surface of radius $r$, $\Delta G=2 \gamma V / r$. Now, assuming the gas to be ideal and relating the free energy to vapor pressure, since $\Delta G=\int v a p$ and $\mathrm{V}=\mathrm{RT} / \mathrm{P} \quad \mathrm{dG}=(\mathrm{RT} / \mathrm{P}) \mathrm{dP}=\mathrm{RTd}(\ln \mathrm{P})$ and $\mathrm{G}=\mathrm{RT} \ln \left(\mathrm{P} / \mathrm{P}^{\circ}\right)$ $\therefore \operatorname{RT} \ln \left(\mathrm{P} / \mathrm{P}^{\circ}\right)=2 \gamma \mathrm{V} / \mathrm{r}$ since $\mathrm{V}=\mathrm{M} / \mathrm{e}$ this equation may also be written in the form above: $\ln \left(P / P^{\circ}\right)=2 M r / R T e_{r}$. According to Adamson (22), "For water, $P / \mathrm{P}^{\circ}$ is about 1.001 if $r$ is $10^{-4} \mathrm{~cm}, 1.011$ if $\mathrm{r}$ is $10^{-5} \mathrm{~cm}$, and 1.114 if $\mathrm{r}$ is $10^{-6} \mathrm{~cm} . "$ Thus, Kelvin curvature effects are apparent only in 
droplets with diameters of $0.1 \mu$ or less.

The Kelvin equation also applies to crystals. Though crystals are polyhedrons in which the faces may have different surface tensions, according to the wulff theorem for an equilibrium crystal $\gamma_{i} / r_{i}$ is a constant where $\gamma_{i}$ is the surface tension of face $i$ and $r_{i}$ is the radius of the circle inscribed in face $i$ (22). Thus, for a crystal $\ln \left(a / a^{\circ}\right)=2 \gamma \mathrm{M} / \mathrm{RT}$ Cr where a=activity of solute in a solution produced with particles of radius $r ; \dot{a}=$ activity of the solute in a solution produced with particles at infinite extent or sufficiently large radius for $1 / x$ to be negligible; $\gamma=$ surface tension of the solute; M=molecular weight of the solute; $R=g a s$ constant; $T=a b s o l u t e$ temperature; $e=d e n s i t y$ of the solute and $r=$ the radius of the inscribed sphere. Since solubility is used to measure activity this equation states that small crystals should have a higher solubility than large crystals in a given solvent. Or, in other words, small particles are in equilibrium with higher concentrations of solution than are large particles. As mentioned previously, this results in vapor pressure lowering according to Raoult's Law. It was found that the Kelvin solubitity effect was 18 for a $0.61 \mu$ particle, 58 for a $0.12 \mu$ particle and 108 for $a$ $0.06 \mu$ particle. Thus, particles of $0.1 \mu$ or less would be expected to show significant Kelvin solubility effects.

Thus, the vapor pressure increase due to droplet 
curvature for drops having a small radius and the vapor pressure lowering which results from increased solubility of small particles have opposing effects on hydration. Figure 4 is a graphic illustration of the divergent effect of Kelvin vapor pressure increase and solute vapor pressure lowering as given by Friedlander (23).

A graphic illustration of the $\mathrm{NaCl}$ hydration process for various particle sizes and at pressures below 1008 relative humidity is given by Orr, Hurd and Corbett(8), see Figure 5. Segment A of these curves represents particle growth due to adsorption. Segment $B$ represents the rapid droplet formation and growth characteristic of deliquescent particles at hydration pressure. At any relative humidity above the water vapor pressure of the saturated solution surrounding the particle, water adds to the film diluting the film and causing further salt dissolution. This in turn reduces the particle size and lowers the vapor pressure as described above causing further water addition. This process, represented by segment $B$, continues until the salt ia totally dissolved. Once the salt is totally dissolved only the solvent effect on vapor pressure (Raoult's Law effects) of the solution, which is continuously diluted by condensing water, needs to be considered. This portion of the hydration process is described by curve $C$. Segment $D$ of this curve illustrates the well known hysteresis: recrystalization does not occur 


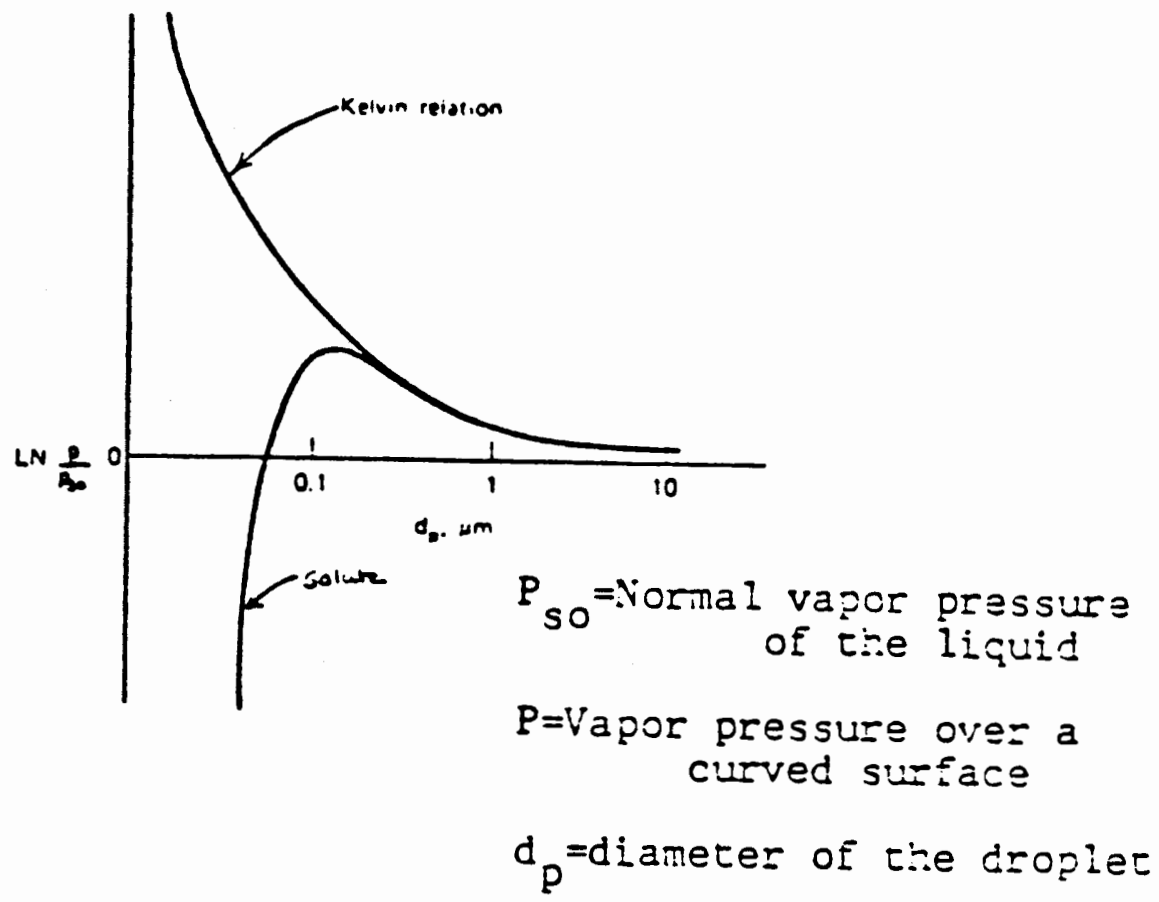

Eigure 4. Equilibrium vapor pressure curves for droplets composed of solvent alone (Kelvin relation) and of a solvent with a fixed mass of non-volatile solute (23) 


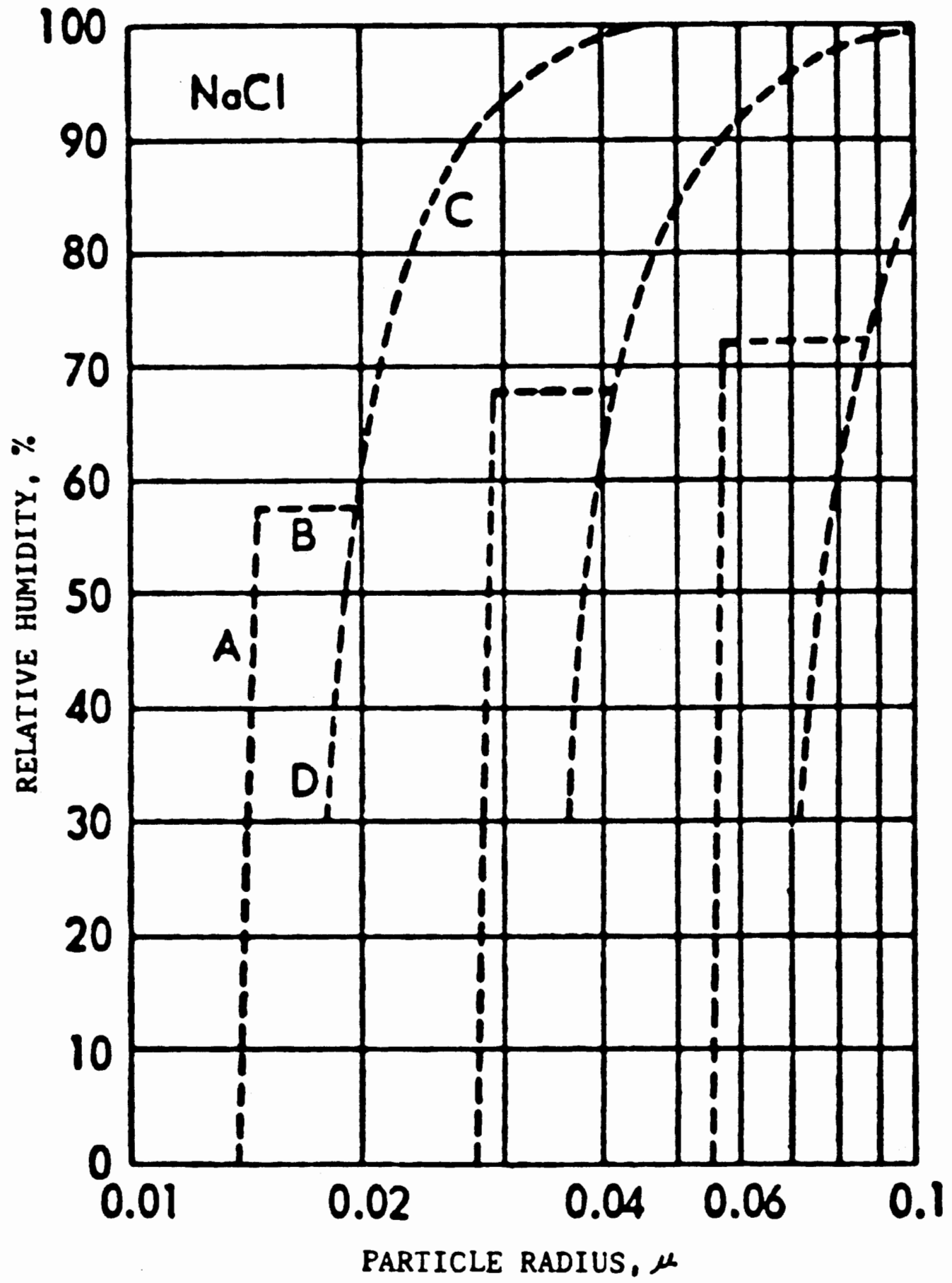

Elgure 5. Sodium chloride hydration curves 
at the same relative humidity as hydration. As the ambient relative humidity is decreased, curve $\mathrm{C}$ is followed. Below the point where line $B$ intersects curve $C D$ the solution is supersaturated and follows curve D. No method of predicting the relative humidity at which this supersaturated solution spontaneously recrystalizes is known. Furthermore, these hydration curves for various particle sizes illustrate that small particles would be expected to hydrate at a vapor pressure below that at which bulk particles will hydrate, as would be expected from the fact that they are in equilibrium with higher concentrations (resulting in greater vapor pressure lowering) of solution due to their increased solubility.

Due to the higher solubility, or alternatively, the higher activity of small particles as given by the Kelvin equation for crystals, recrystalization to one large crystal rather than several small crystals would be expected.' In fact, however, this is not always what was observed. These experiments illustrated that kinetic effects may dominate the thermodynamic considerations during recrystalization with resultant crystal shattering. The phenomena of crystal shattering will be discussed later in this thesis in regard to kinetic considerations. 
Since the video recorder was able to record one image every sixtieth of a second and particle diameters could be measured from the video screen, the change in droplet diameter with time could be found. A computer model of the kinetics of sodium chloride hydration was derived.

The initial dissolving rate of a soluble material at any given temperature is expected to be proportional to its surface area. This relationship was illustrated for sodium chloride by G. W. Gleeson (24). Gleeson proposed that a thin layer of saturated solution was immediately adjacent to the solid surface and that a concentration gradient existed out to a concentration equal to the concentration of the bulk solution. Furthermore, it is the diffusion rate of solute across this concentration gradient as well as a surface reaction which controls the dissolving rate of the soluable solid. Gleeson states,

According to the Berthoud-Valeton Theory, the rate of solution of a crystalline substance depends upon rate of diffusion and a first order surface reaction. This fact can be most simply expressed as,

$\mathrm{dW} / \mathrm{de}=\mathrm{KS}\left(\mathrm{C}-\mathrm{C}_{\theta}\right)$

where $W$ is the weight of undissolved solute

$\theta$ is the time

$S$ is the surface area of the undissolved solute

$\mathrm{C}_{\mathrm{s}}$ is the concentration of solute in solution at saturation

$C_{\theta}$ is the concentration of solute in solution at time o

$K$ is a constant

In obtaining experimental data for the dissolving 
rate of sodium chloride Gleeson mixed the solution surrounding the salt cube. Due to this mechanical mixing a uniform concentration of solution surrounded the saturated solution layer adjacent to the salt cube. Though mechanical mixing does not take place in the experimental work for this thesis, it is shown in the derivation of the kinetic model that the liguid phase diffusion rate is rapid and thus the saline concentration surrounding the saturated liquid layer adjacent to the salt cube is homogenous. Using Fick's first law and a random walk calculation the diffusion coefficient $D$ may be defined: $D=x^{2} / 2 t$ where $x=t h e$ distance through which the particle diffuses in time $t$. $O r$, alternatively $t=x^{2} / 2 D$. Using 1.2 $\mathrm{g} / \mathrm{cm}^{3}$ for a saturated solution density, $0.36 \mathrm{~g} / \mathrm{cm}^{3}$ for the solubility of sodium chloride and extrapolated data from M. W. Kellogg Co. (25) a value of $D=4 \times 10^{-6} \mathrm{~cm}^{2} / \mathrm{sec}$ was obtained for the diffusion coefficient of sodium chloride through a saturated solution of sodium chloride at $25^{\circ} \mathrm{C}$. Using that value of $D$ it was calculated that it requires approximately $1.25 \times 10^{-3}$ seconds for the salt to diffuse one micron. Mixing is also aided by the temperature gradient which normally exists in the solution. During hydration which results in the salt dissolving, there is cooling at the salt surface due to the endothermic process of salt solution and warming at the droplet surface due to the exothermic process of condensation. Likewise, during 
dehydration and salt recrystalization warming due to exothermic recrystalization occurs at the salt surface and cooling due to endothermic evaporation occurs at the droplet surface. In both cases a temperature gradient and resultant thermal mixing occur. Thus, the rate constant and rate equation described by Gleeson were used to describe the salt dissolution process in the experimental work for this thesis.

To experimentally determine the rate constant for this process Gleeson used the relationship that for geometrical solids the surface area is proportional to the weight raised to the $2 / 3$ power:

$\mathrm{W}=\mathrm{Ve}$ $S=$ surface area

$w=1^{3} e$

W=weight

$W^{2 / 3}=e^{2 / 3} 1^{2}$

$\mathrm{V}=$ volume

$W^{2 / 3}=e^{2 / 3} / 6\left(61^{2}\right)$

l=length

$W^{2 / 3}=\left(e^{2 / 3} / 6\right) s$

$61^{2}=$ surface area of a cube

$S=6 / e^{2 / 3}\left(W^{2 / 3}\right)$

$e=$ density of sodium chloride

Thus, the proportionality constant is $6 / e^{2 / 3}$. Using this relationship $d W / d t=K^{\prime} W^{2 / 3}\left(C_{s}-C\right)$ where $t=t i m e$ and $C=C_{\theta}=$ concentration of solute in solution at time $t$. And, using Gleeson's experimental data, $K^{\prime}$ was determined to be $0.462 \mathrm{~cm}^{3} / \mathrm{min}-\mathrm{g}^{2 / 3}$. For the purposes of this thesis, however, it was desired to know the change in the number of moles of sodium chloride rather than the weight of sodium chloride with time: 
$\mathrm{W}=(\#$ moles $)(\mathrm{MW})$

$\mathrm{MW}=$ molecular weight of $\mathrm{NaCl}$

$d W=M W($ dmoles $)$

$\mathrm{C}_{\mathrm{S}}=$ the concentration of solute

(MW) dmoles/dt $=K$ W $\left(C_{s}-C\right)$ in solution at saturation

But $w^{2 / 3}=\left(e^{2 / 3} / 6\right) s$ $C=C_{\theta}=$ the concentration of solute (MW) dmoles $/ \mathrm{dt}=\mathrm{K}\left(e^{2 / 3} / 6\right)\left(\mathrm{C}_{s}-\mathrm{C}\right) \mathrm{s}$ in solution at time $t$ dmoles $/ \mathrm{d} t=\mathrm{K}\left(1 / \mathrm{MW}_{\text {sait }}\right)\left(e_{\text {sat }}^{2 / 3} / 6\right)\left(\mathrm{C}_{\mathrm{s}}-\mathrm{C}\right) \mathrm{s}$

Let $K^{\prime}\left(e_{\text {wit }}^{2 / 3} / 6\right)=K 2$

$\mathrm{K} 2=\left(0.462 \mathrm{~cm}^{3} / \mathrm{min}^{2 / / 3}\right)(1 \mathrm{~min} / 60 \mathrm{sec})(1 / 6)\left(2.163 \mathrm{~g} / \mathrm{cm}^{3}\right)^{2 / 3}$ $\mathrm{K} 2=2.14 \times 10^{-3} \mathrm{~cm} / \mathrm{sec}$

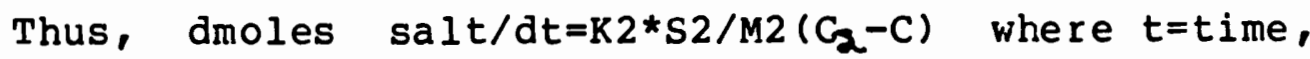
$\mathrm{K} 2=$ rate constant in $\mathrm{cm} / \mathrm{sec} \mathrm{S} 2=$ the surface area of the salt cube in $\mathrm{cm}^{2}, M 2=$ mass of sodium chloride, $C_{2}=$ saturated salt concentration in $\mathrm{g} / \mathrm{cm}^{3}$, and $\mathrm{C}=$ concentration of salt at time $t$ in $\mathrm{g} / \mathrm{cm}^{3}$.

Now that an expression for the flux of salt was worked out, an expression for the flux of water, that is the change in the number of moles of water adding to the droplet per unit time, was needed. Just as the dissolution of the salt may be surface or diffusion controlled, the droplet growth rate may also be surface or diffusion controlled. Whether evaporation is surface or diffusion controlled is dependent upon droplet size and the pressure gradient. Consideration of the diffusion of water vapor to the droplet is somewhat more complicated than the salt diffusion through the liguid droplet since one equation can not be used to describe all types of gas 
phase diffusion. When discussing diffusion properties, particles are generally classified by their Knudsen number. Knudsen number, $K n$, is defined as $1 / d$ where $l=$ the mean free path of the gas or the mean distance traveled by a molecule between successive collisions (may be calculated from the kinetic theory of gases), and d=the diameter of the drop. Three classes of gas phase diffusion exist: (I) when $1 / d \gg>1$ or $K n \gg l$ (II) when $1 / d<<I$ or $k n<<l$ and (III) when $\mathrm{Kn} \cong 1$.

The class of gas phase diffusion when $1 / d>1$ or $k n \gg 1$ is known as the free molecular range or the knudsen regime. In picturing a water molecule or small group of water molecules traveling through the water vapor toward the saline droplet, it is obvious that when the diameter of the droplet is much smaller than the mean free path, $1 / d$ or $K n \gg>1$, any molecules bouncing from the surface of the saline droplet would be unlikely to collide with the entering water molecules until far from the droplet surface. Thus, most of the water molecules striking the droplet are essentially unaffected by the presence of the sphere. Therefore, molecular collision theory can be used to describe the flux of water in the free molecular range. When the droplet diameter is much greater than the mean free path of the diffusing particle, $1 / d$ or $K n<<1$, molecules striking the surface are strongly affected by those leaving and other surrounding molecules. Under these 
conditions the particles display diffusive behavior and the Maxwell equation may be used to describe the diffusion. The Maxwell equation is derived from Fick's first and second laws of diffusion (26). If the droplet is small or if the pressure gradient between the vapor pressure at the droplet surface and the ambient pressure is great the rate at which molecules can leave the surface of the drop may be much slower than the diffusion rate from the surface as predicted by Maxwell's equation.

Thus, collision theory may be used to predict the flux of water at a drop's surface and the Maxwell equation may be used to predict the flux of water to the drop's surface but neither is satisfactory for the transition range where $1 / \mathrm{d}$ or $\mathrm{Kn} \cong \mathbf{I}$. To deal with this intermediate area Fuchs defined a distance $\Delta$ which is approximately equal to the mean free path. The Fuchs equation is a semiempirical equation. Table I provides a review of the three classes of gas phase diffusion.

From Table I it can be seen that the knudsen and Maxwell equations differ only by an $\alpha / 2$ and $k n$ or $1 / d$ factor. Furthermore, if the limits of the Fuchs equation are looked at in the limit where $\mathrm{Kn} \gg \mathrm{I}$ the equation reduces to $1 / K n$ or $\partial d / \partial t=f(d)$ and in the limit where $K n<l l$ the equation reduces to simply the Maxwell equation as it must to describe the intermediate region of gas kinetics. In this thesis the collision equation was used in 
TABLE I

GAS PHASE KINETICS EQUATIONS

FOR SPHERICAL PARTICLES (DROPLETS)

$$
\mathrm{Kn}=1 / \mathrm{d}
$$

Kn $>1$ Free Molecular(Knudsen) small particle-low $P$ Flux (\#collisions $\left./ \mathrm{cm}^{2}-\mathrm{sec}\right)=(1 / 4) \mathrm{n} \bar{c} \alpha$ $\partial d / \partial t=(\alpha \bar{c} / 2)(V m)(\Delta n) \quad \partial d / \partial t \not f(d)$

$\mathrm{Kn} \ll<1$ Diffusive (Maxwell) large particle-high $P$ $0=\partial c / \partial t=\left(D / r^{2}\right) \partial / \partial r\left(r^{2} \partial c / \partial r\right)=D\left((2 / r) \partial c / \partial r+\partial^{2} c / \partial r^{2}\right)$ $\partial d / \partial t=(-2 D / d)(V m)(\Delta n)=\bar{c} V m \Delta n K n \quad \partial d / \partial t=f(1 / d)$

$\mathrm{Kn} \stackrel{\sim}{=}$ Semiempirical Equation(Fuchs $\Delta$ )

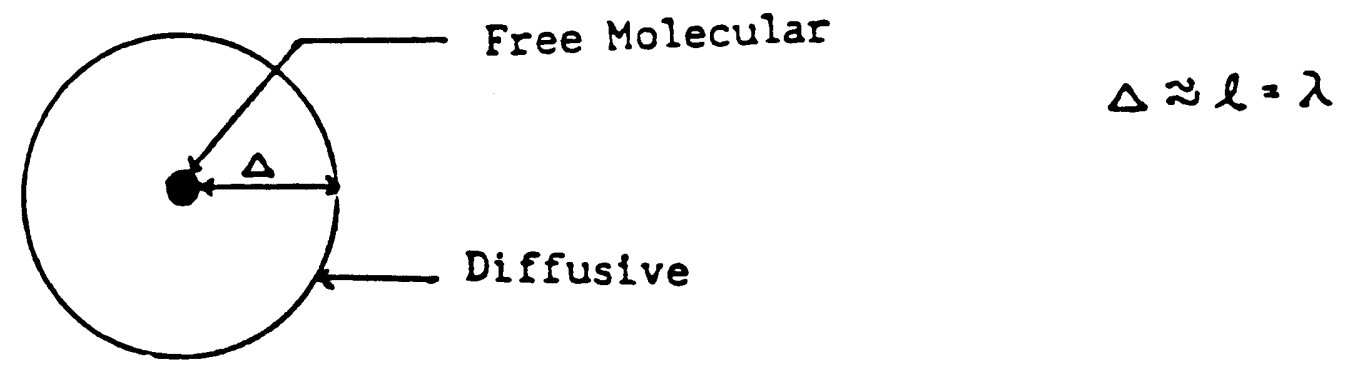

$\partial d / \partial t=(\partial d / \partial t)$ Diffusive $/(1+K n(2.666 K n+1.42) /(1+K n))$ $\partial d / \partial t=f(K n / d)$

$l=$ mean free path of molecules in the gas pgase $d$ diameter of the drop 
Table I continued

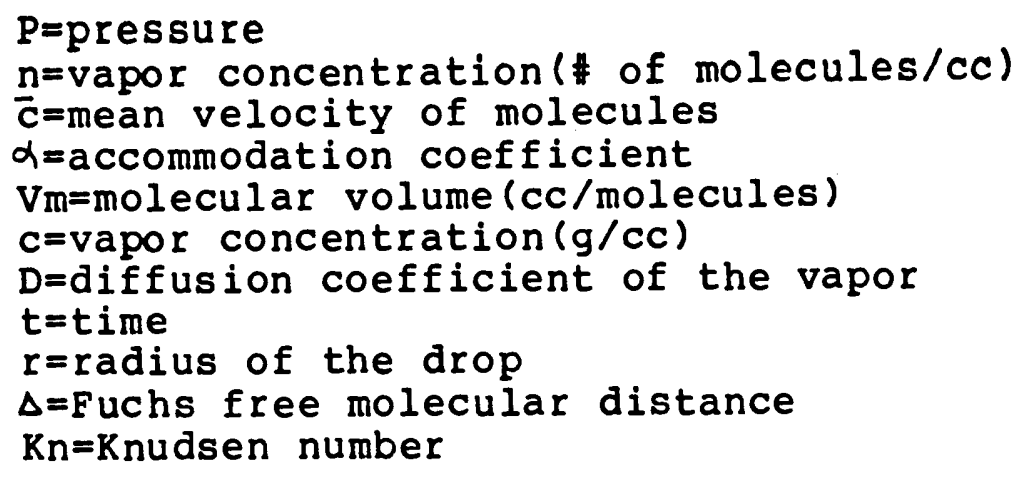


the development of the theoretical model. The collision equation or gas kinetic method of calculating the flux of water was used because it is applicable for small particles and low pressures and includes surface effects on the flux of water through the surface area term in the collision equation. In fact, the accommodation coefficent is also dependent on the droplet size as described by zung (27). The Maxwell equation was not used because it is applicable only to large particles and considers only the diffusion and not the surface effect on the flux of water. The Fuchs equation would have been a more complete expression for the water flux but it is a semiempirical equation. A more complete discussion of the surface versus diffusion effects on the evaporation of droplets is given by Joseph T. Zung (27). Therefore, in this thesis it was assumed that the gas phase was not diffusion limited (assume Knudsen deposition on the droplet). It was also assumed that equilibrium between the liquid surface and the gas phase in terms of vapor pressure lowering is rapid and is described by $\mathrm{Pl}=(\mathrm{Al}) \mathrm{PO}$ where $\mathrm{Pl}$ =water vapor pressure above the droplet, $A l=a c t i v i t y$ of water in the droplet, and P0=pressure of pure water vapor at the experimental temperature. Under these conditions, the number of collisions of water molecules per square centimeter of droplet surface per second is given by the standard collision equation: \#collisions $/ \mathrm{sec}-\mathrm{cm}^{2}=0.25 \times n \bar{c}$ 
where $n=t h e$ concentration of water molecules and $\overline{\mathrm{C}}=$ relative speed $\overline{\mathrm{C}}=4 \sqrt{\mathrm{KT} / 2 \pi \mathrm{m}}$ where $\mathrm{K}=$ Boltzman's constant $=1.38066 \times 10^{-23} \mathrm{~J} / \mathrm{K} \mathrm{T}=$ absolute temperature and mass of a water molecule, $\alpha$ =accommodation coefficient. Thus, \#collisions/sec $=0.25 \alpha \mathrm{n} \overline{\mathrm{CS}} \mathrm{l}$ where $\mathrm{Sl}=$ the surface area of the droplet. If the concentration of water molecules $n$ is expressed in moles $/ \mathrm{cm}^{3}$ then \#moles of water/sec $=0.25 \alpha \mathrm{nc} S \mathrm{~s}$. The concentration of water molecules, $n$, is given by $P-P 1$ where $\mathrm{P}=$ the ambient water vapor pressure in moles $/ \mathrm{cm}^{3}$ and $\mathrm{Pl}=$ the water vapor pressure above the droplet expressed in moles $/ \mathrm{cm}^{3}$. Thus the flux of water may be expressed: flux $=$ dmoles $\mathrm{H}_{2} \mathrm{O} / \mathrm{dt}=0.25 \overline{\mathrm{c}}(\mathrm{P}-\mathrm{Al}(\mathrm{PO})) \mathrm{Sl} \alpha$

Now that expressions for both the flux of water and the flux of salt were derived, the expressions can be numerically integrated and the diameter of the droplet, the length of the salt cube and the flux rates at a given time can be calculated. Kelvin considerations for vapor pressure increase due to curvature and increased salt solubility due to curvature were also considered in the numerical integration. For more complete details concerning the computer program, written in basic, which was used to perform the numerical integration on the Honeywell computer see appendix B.

The kinetic expressions mentioned above are applicable until the salt is completely dissolved. At that point, F2=0 and the flux of water with its resultant 
dilution of the solution (and thus reduction of vapor pressure lowering due to lower solute concentration) is the process which controls the kinetics of the hydration. Numerical integration of Fl and the proper calculations (as described in appendix $B$ ) again yield the rate of change of droplet diameter with time and the diameter of the droplet at any given time.

Activity data were necessary for dilute through supersaturated sodium chloride solutions. However, only literature values for the activity of water in sodium chloride solutions up to saturation could be found. It is also known that the activity of water is zero when the mole fraction of salt in solution is one. Thus, a cubic spline method was used to fit a curve which predicted water activity as a function of the mole fraction of salt in the supersaturated region. Using this method, a cubic equation was first fit to the available activity data, the activity of water in sodium chloride solution up to a mole fraction of 0.0975 . It is also known that when the mole fraction of salt in solution is one the water activity is zero and the slope of the cubic fit for the activity data for supersaturated solutions must be zero at the point where the mole fraction of salt equals one. Thus, the cubic equation which fits the supersaturated part of the curve: $a+b(x 2)+c(\times 2)^{2}+d(\times 2)^{3}=A 1$ where $\times 2=$ mole fraction of salt in solution and Al=activity of water, has the form 
$a+b+c+d=0$ when $\times 2=1$ and $a$ slope of $b+2 c+3 d=0$ when $\times 2=1$. There must also be no inconsistancy where the cubic expression for the supersaturated activities meets the cubic equation which was already fit to the activity data for solutions which are less than saturated. Thus, the cubic equation for supersaturated solution water activities must have the same solution and slope as the most concentrated point in the cubic equation for water activities of less than saturated solutions. For this particular data those equations are: (solution) $a+9.75 E-2 b+9.5062 E-3 c+9.268 E-4 d=0.76$ and (slope) $b+0.195 c+2.85186 E-2 d=-3.33$ Thus, these four equations may be solved simultaneously (using matricies) for the four coefficients of the equation which will fit the water activity versus mole fraction in the supersaturated region. The resultant equation for the activity of water for supersaturated sodium chloride solutions is: $\mathrm{Al}=1.3-4.281 * \times 2+5.1711 * \times 2^{2}-2.021 * \times 2^{3}$. Various theories may be used to predict the activity coefficients of electrolytes. The simplest of these theories is the Debye-Huckel theory. The Debye-Huckel theory, however, considers only coulombic attractions and repulsions and thus is a limiting law at low concentrations. The activity coefficient of an electrolyte is very concentration dependent and theories to predict activity coefficients in the saturated and supersaturated regions must consider 
other intermolucular forces resulting in far more complicated equations than the Debye-Huckel equation. It was thus decided to carry out the integration using experimental data and the resultant equations obtained by fitting the experimental data for less than saturated solutions and using the cubic spline methhod of predicting activity data in the supersaturated region.

The computer model and discussion of kinetics thus far have dealt with the kinetics of sodium chloride hydration. Upon lowering water vapor pressure and resultant dehydration the same kinetics should be applicable down to the pressure at which hydration began. However, as previously discussed there is hysteresis in recrystalization. During these experiments one of two things was observed upon dehydration: (I) the salt particle recrystalized within 0.1 seconds to a central crystal (some residue was also observed around the cryatal probably due to surface nucleation) or (II) the particle shattered.

The recrystalization of sodium chloride upon dehydration was generally observed only with larger salt crystals. It is reasonable, therefore, that the salt cube had not totally dissolved during hydration. Thus, during dehydration the sodium chloride in solution recrystalized on to the remaining "seed" crystal. On the other hand, those crystals which shattered were generally smaller and 
therefore probably were totally dissolved during hydration.

Henri Dessens noted rare occurrences of crystal shattering or explosions back in 1949 (4). Detection of, or evidence for, crystal shattering was later illustrated by Twomey and Mc Master (1); Dinger, Howell and Wojciechowski (28) and Radke and Hegg (29) though Lodge and Baer (30) and Blanchard and spencer (31) detected no crystal shattering during their experiments. However, the shattering or explosion of sodium crystals upon crystalization is not unreasonable. Using data from Adamson (32) it was found that the reaction $\mathrm{Na}^{+}+\mathrm{Cl}^{-}--->$ $\mathrm{NaCl}$ is exothermic with $\Delta \mathrm{H}_{298}=-4.14 \mathrm{~kJ} / \mathrm{mole}$. As mentioned earlier in cases where explosions occur it is assumed that there is no seed crystal. Since hysteresis of recrystalization occurs, the droplet solution concentration is supersaturated prior to crystalization. Thus, when cryatallization is initiated it proceeds spontaneously and probably very rapidly. Though a large amount of heat is not given off, the reaction is exothermic and if the reaction proceeds rapidly enough and the heat is not removed rapidly enough the temperature of the solution goes up causing the rate of evaporation to increase thus increasing the salt concentration and driving the recrystalization thus generating more heat and so on until thermal explosion results. This type of 
behavior is possible for all those cryatalline substances like NaCl that have positive heats of solution.

Another possible explanation for crystal shattering is evaporative cooling. If the evaporation of water with resultant evaporative cooling rather than heat generation by recrystalization was the dominant effect, crystal freezing and shattering may result. Samuel Glasstone calculated the latent heat of vaporization: $\mathrm{H}_{2} \mathrm{O}(1)-->\mathrm{H}_{2} \mathrm{O}\left(\mathrm{g}, \mathrm{l} \mathrm{atm}\right.$ ) $\Delta \mathrm{H}_{298}=10.52 \mathrm{Kcal} / \mathrm{mole}=44.04 \mathrm{KJ} / \mathrm{mole}$. Thus, the theoretical model of hydration/evaporation proposed in this thesis and the predicted rate of salt recrystalization and evaporation can help elucidate which of the two proposed mechanisms of crystal shattering is the most probable. 


\section{CHAPTER IV}

\section{RESULTS AND DISCUSSION}

Two major objectives existed in the analysis of sodium chloride hydration data: first, data obtained by Antony Clarke (34) in a manner similar to the procedure described in this thesis were analyzed relative to their kinetic rates, and second, data were obtained using very small pressure gradients in an attempt to determine whether thermodynamic or kinetic effects were dominant in the initiation of hydration

Three sets of data obtained by Antony Clarke were analyzed. These data are tabulated in Tables II, III, and IV and presented graphically in Figures 6, 7, and 8 respectively. In Figure 6 hydration was proceeding until almost 4 seconds, then the pressure was suddenly rapidly reduced. At approxomately 4.5 seconds the pressure was rapidly increased. Thus, the area of Figure 6 between 4 and 5 seconds represents the results of a large pressure gradient. The data tabulated in Tables III and IV represent hydrations with no pressure reduction or consequent dehydration. The pressures used during hydration were not accurately measured. However, for 
TABLE II

EXPERIMENIAL DATA (34)

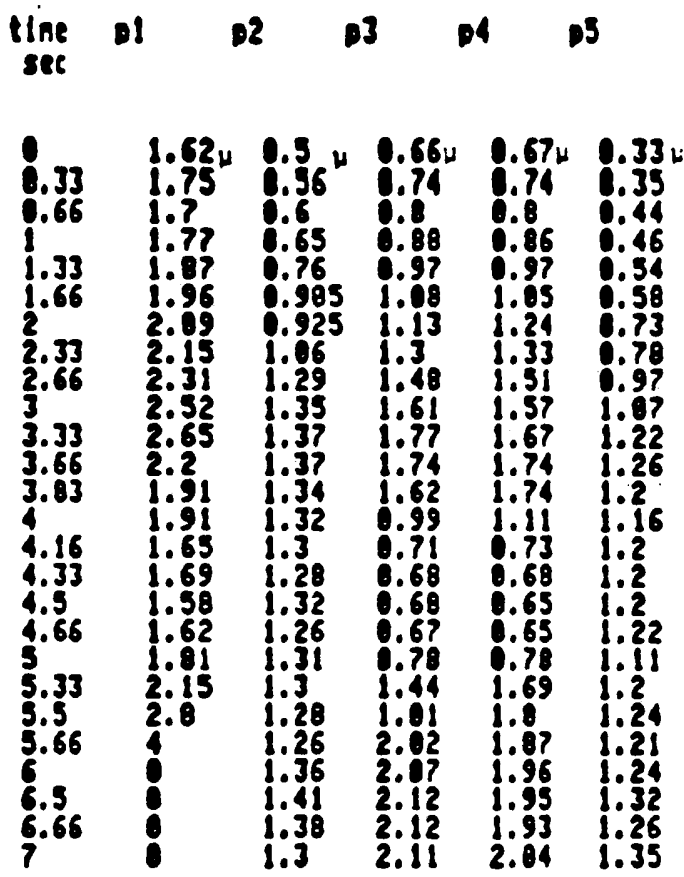

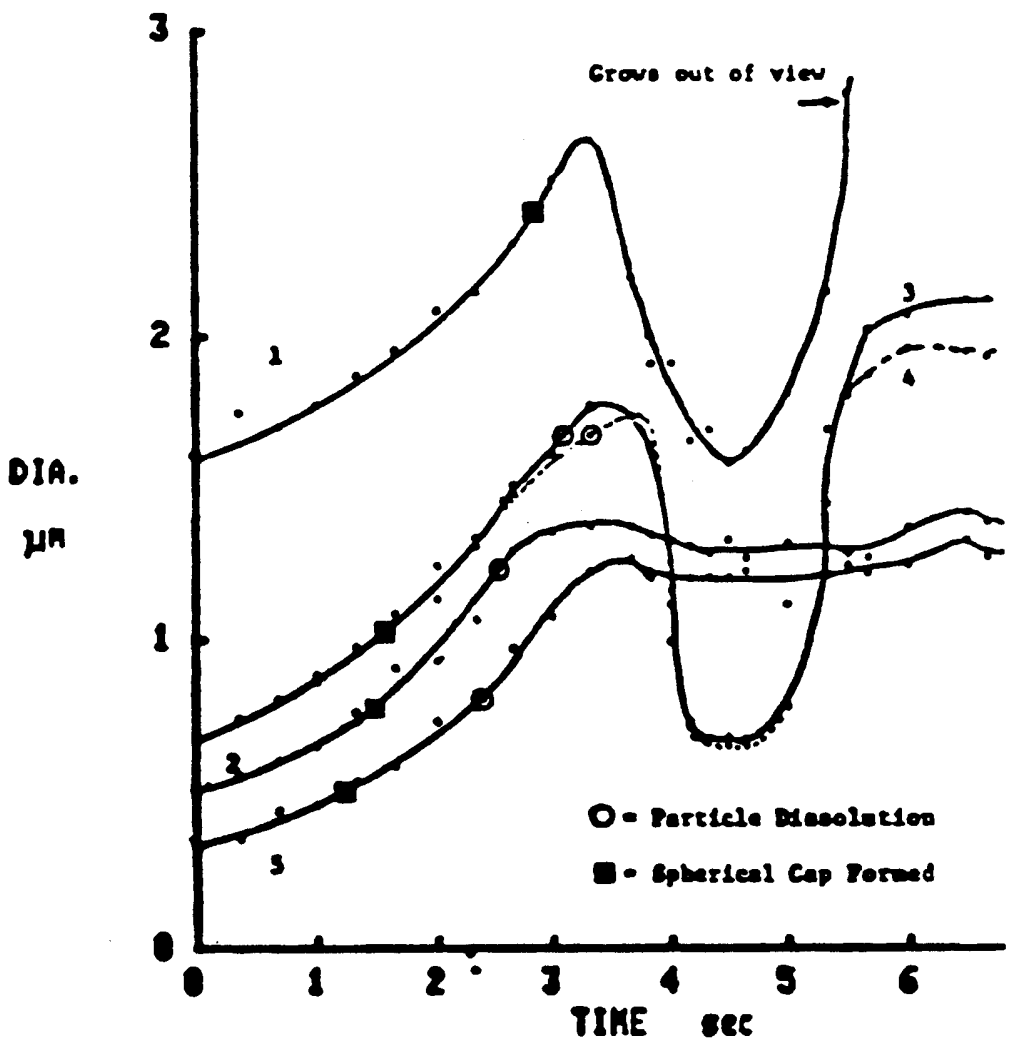

Eleure 6. Graphic representation of data In Table II (34). 
TABLE III

EXPERIMENTAL DATA (34)

$\underset{\text { tinec }}{t}$ of $02 \quad 03 \quad 04 \quad$ D5

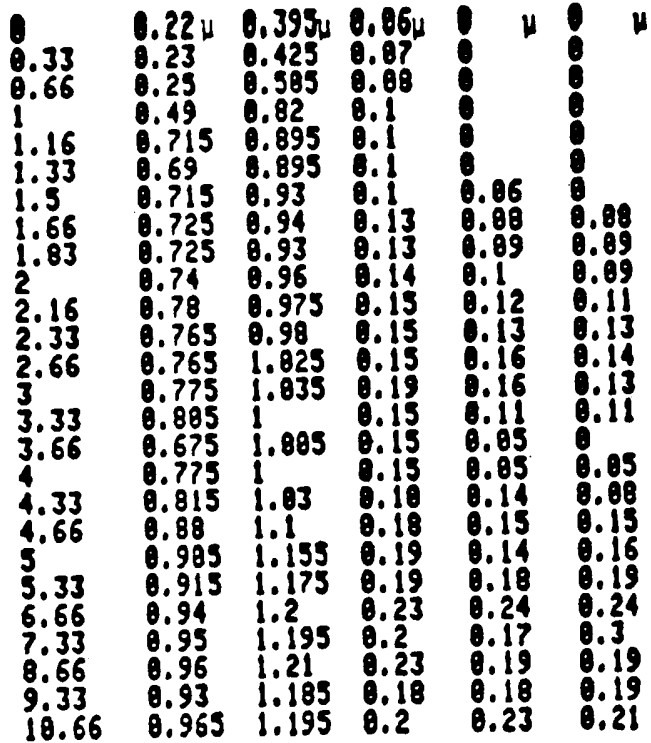

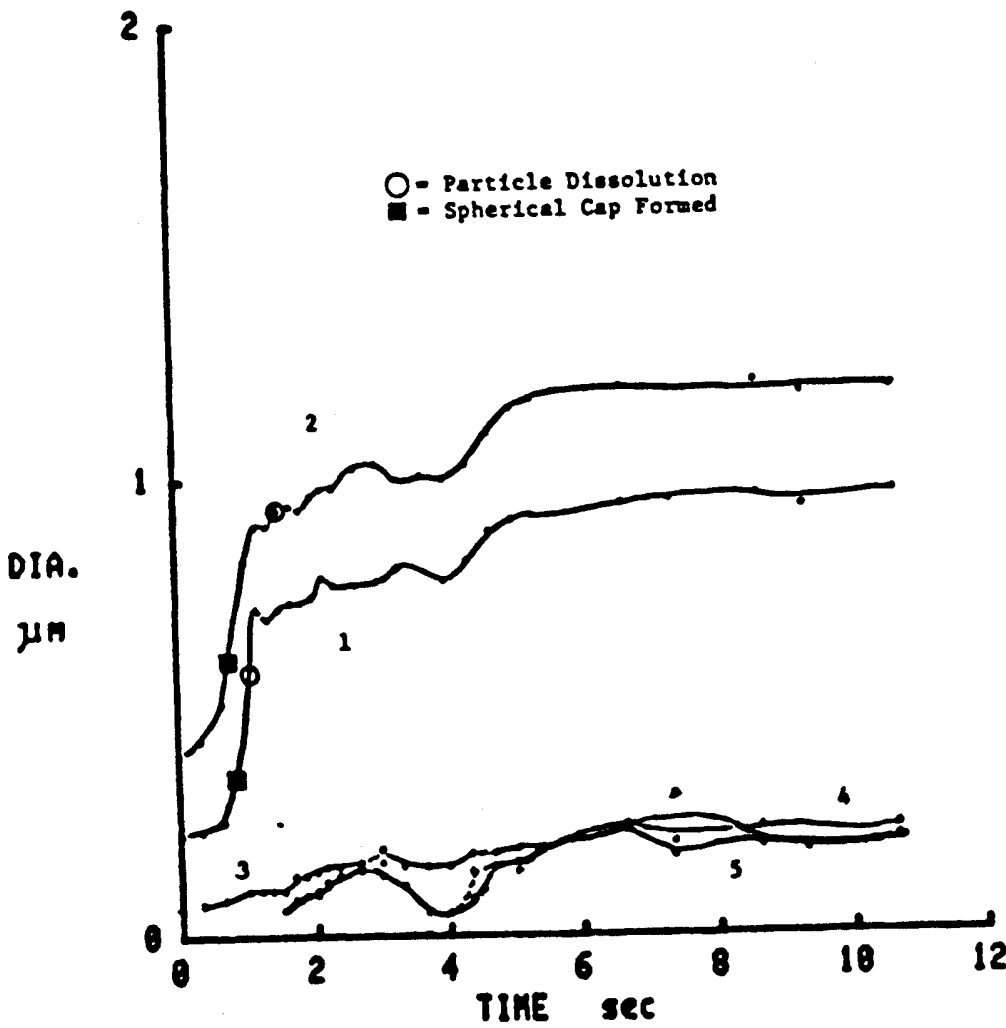

Figure 7. Graphic representation of data in Table III (34). 
TABLE IV

EXPERIMENTAL DATA (34)

\begin{tabular}{|c|c|c|}
\hline sec & 01 & $\begin{array}{l}02 \\
1 C_{\mu}^{-1}\end{array}$ \\
\hline $\begin{array}{l}33 \\
.66 \\
.66 \\
.65 \\
.66 \\
.65 \\
.33\end{array}$ & $\begin{array}{l}0.21 \\
8.26 \\
8.28 \\
8.31 \\
8.34 \\
8.38 \\
8.39 \\
8.43 \\
8.41 \\
8.42 \\
8.47 \\
8.43 \\
8.42 \\
8.49 \\
8.55 \\
8.54 \\
8.56 \\
8.54 \\
8.52 \\
8.51 \\
8.52 \\
8.5 \\
8.45 \\
8.51 \\
0.52\end{array}$ & $\begin{array}{l}0.24 \\
0.32 \\
8.37 \\
8.38 \\
8.4 \\
8.48 \\
8.46 \\
8.5 \\
8.54 \\
8.58 \\
0.6 \\
0.59 \\
8.57 \\
8.61 \\
8.68 \\
8.69 \\
8.67 \\
0.69 \\
0.67 \\
8.67 \\
8.69 \\
8.69 \\
8.68 \\
0.7\end{array}$ \\
\hline
\end{tabular}

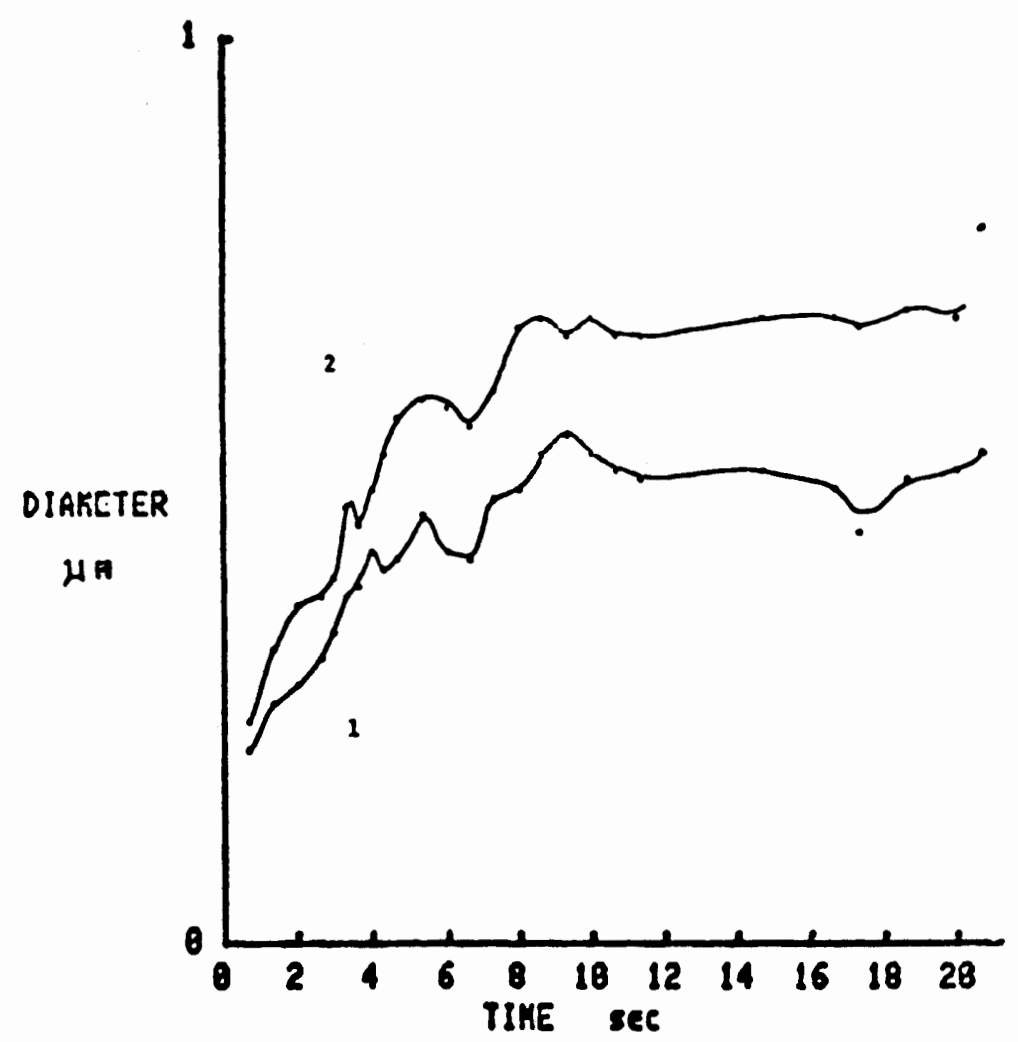

Figure 8. Graphic representation of data in Table IV (34). 
particles which grew to a maximum equilibrium size, the pressure of hydration could be calculated. Since the final droplet diameter was measured, the final droplet volume was known. Thermodynamics require the salt cube to totally dissolve and thus the final concentration of salt in the droplet was calculated. Using activity versus concentration data, the activity of the sodium chloride solution and thus the equilibrium pressure were determined (see Appendix B). Thus, only the accommodation coefficient remained unknown. This author was unable to find a literature value for the accommodation coefficient. Zung (27), however, comments on the nature of the accommodation coefficient:

...the variation of the condensation and
evaporation coefficient $\alpha$ with the radius has been
suggested by Frisch ( 35$)$, and can be shown by
experimental measurements of the rate of
evaporation of small droplets ranging from lo to
$0.01 \mu$ in radius under vacuum. The fact that no
experiment of this nature has been done probably
lies in the diffuculties involved in both the
determination of the size of such a small droplet
and the production of droplets in vacuum.

It was decided to use a single particle and determine an accommodation coefficient value which optimized the fit. Particle 3 listed in Table II was used. The portion of the curve after 5 seconds was fit using the computer simulation and an accommodation coefficient of 0.003 . The computer program simulates the hydration curve from the diameter at which the spherical cap had just formed 
through the final diameter. This simulated hydration curve from the diameter of the spherical cap to the final diameter is the center solid line in Figure 9. It can be seen that an accommodation coefficient of 0.003 yields a very good fit to the experimental data. The top solid line and the bottom solid line in Figure 9 represent simulated curves with the salt dissolution rate constant multiplied and divided by 2 respectively. It can be seen that altering the salt dissolution rate constant does have an effect on the rate and shape of the simulated hydration curve. This simply illustrates that the hydration rate is sensitive to both the salt and the water fluxes.

Since an accommodation coefficient of 0.003 gave very good fit of the simulated hydration curve for particle 3 after 5 seconds, it was used to simulate the other curves in Figure 6. Particle 1 after 5 seconds grew out of view and thus the hydration pressure could not be calculated from this particle. However, since particles 1 and 3 were subjected to the same hydration pressure the hydration pressure calculated from particle $3, \mathrm{H}=89.96$, was used to simulate the growth curve for particle 1. The simulated curves for the particles in Figure 6 are shown in Figure 10. Since the initial hydration, hydration previous to 4 seconds, occurs at a different hydration pressure than the second hydration, hydration after 5 seconds, the final diameters of particles 2,3 , and 5 were 


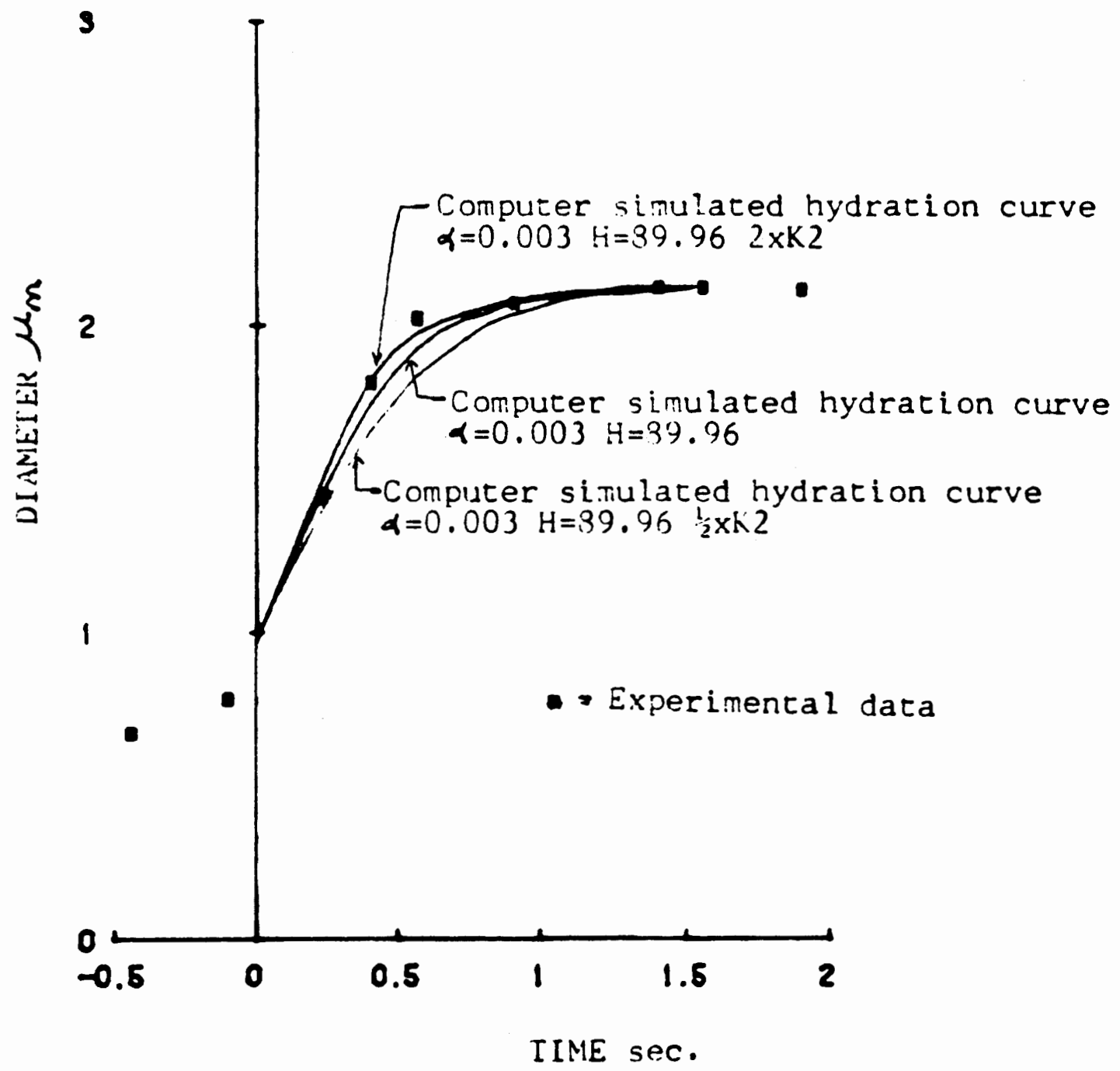

Figure 9. Computer simulated hydration curves for particle 非 3 Table II after 5 seconds. 


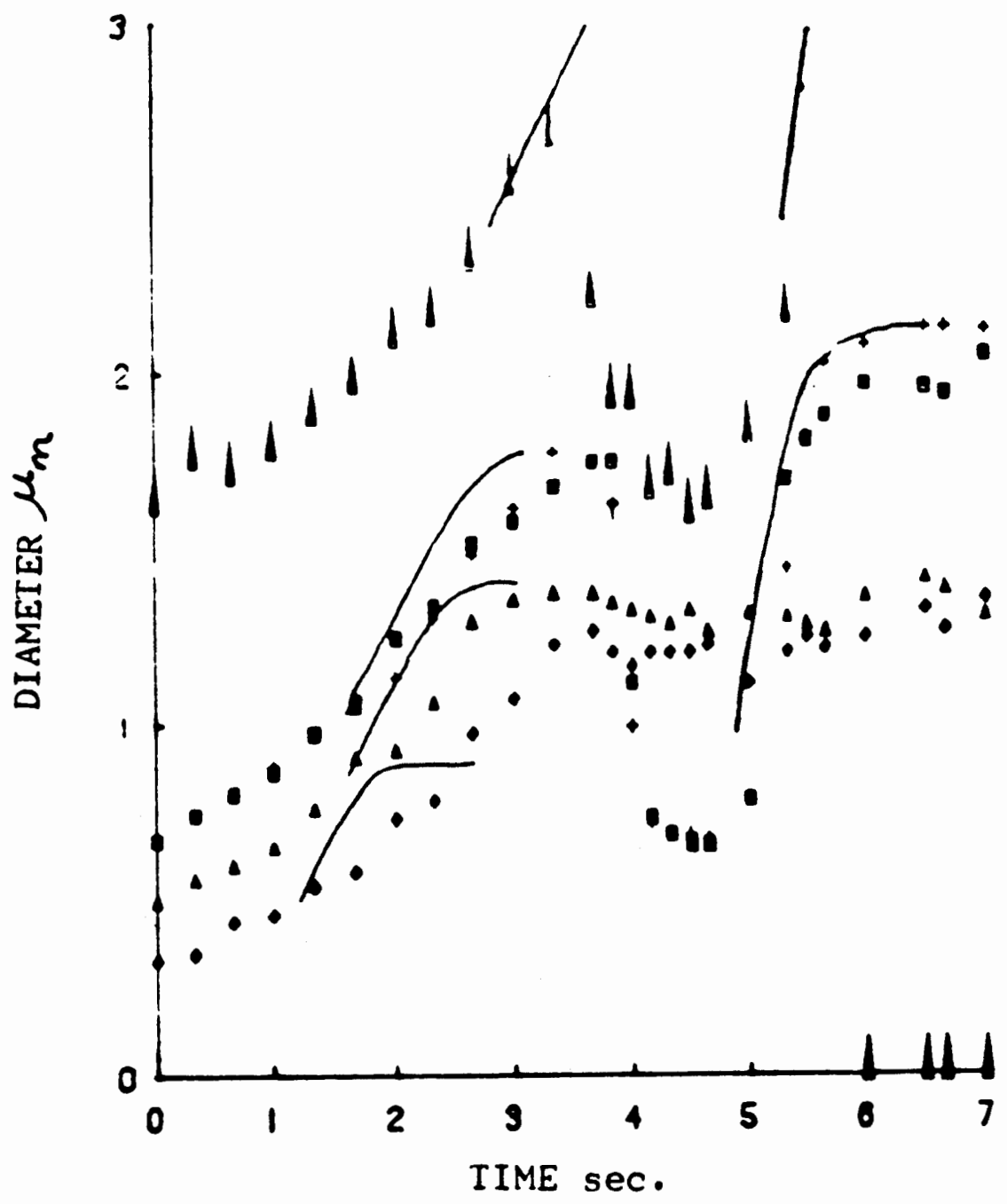

Figure 10. Computer simulated hydration curves for the particles in Figure 6 . 
used to calculate the hydration pressure. Since the final volume of the droplet, and thus $D$ cubed, was used in this calculation, variation in the measurement of $D$ caused even larger variations in the calculated hydration pressure. Since all particles were subjected to the same hydration pressure an average value was used. Thus, to model the hydration curves from spherical cap to maximum size for particles $1,2,3$ and 5 in Figure 6 , an accommodation coefficient of 0.003 and $\mathrm{H}=80$ were used. The simulated growth curves are shown on Figure 10. Close agreement is found for particles 1,2 and 3. Variation between the simulated hydration curve for particle 5 , the smallest particle with $\mathrm{L} 0=0.33 \mu$, and the experimental hydration curve may be due to the particle size dependence of the accommodation coefficient.

Similar calculations were performed for the data in Tables III and IV. Computer simulated hydration curves for the particles in Table III, Figure 7, using an accommodation coefficient of 0.003 and $H=88.0$ are shown in Figure 11. Once again the simulated rate for particle 3, the smallest particle, was too fast. This may indicate that the accommodation coefficient is dependent on particle size with smaller particles having smaller accommodation coefficients. The simulated hydration curve for particle 2 gives an appropriate rate but predicts that the droplet will grow to a larger final diameter than was 


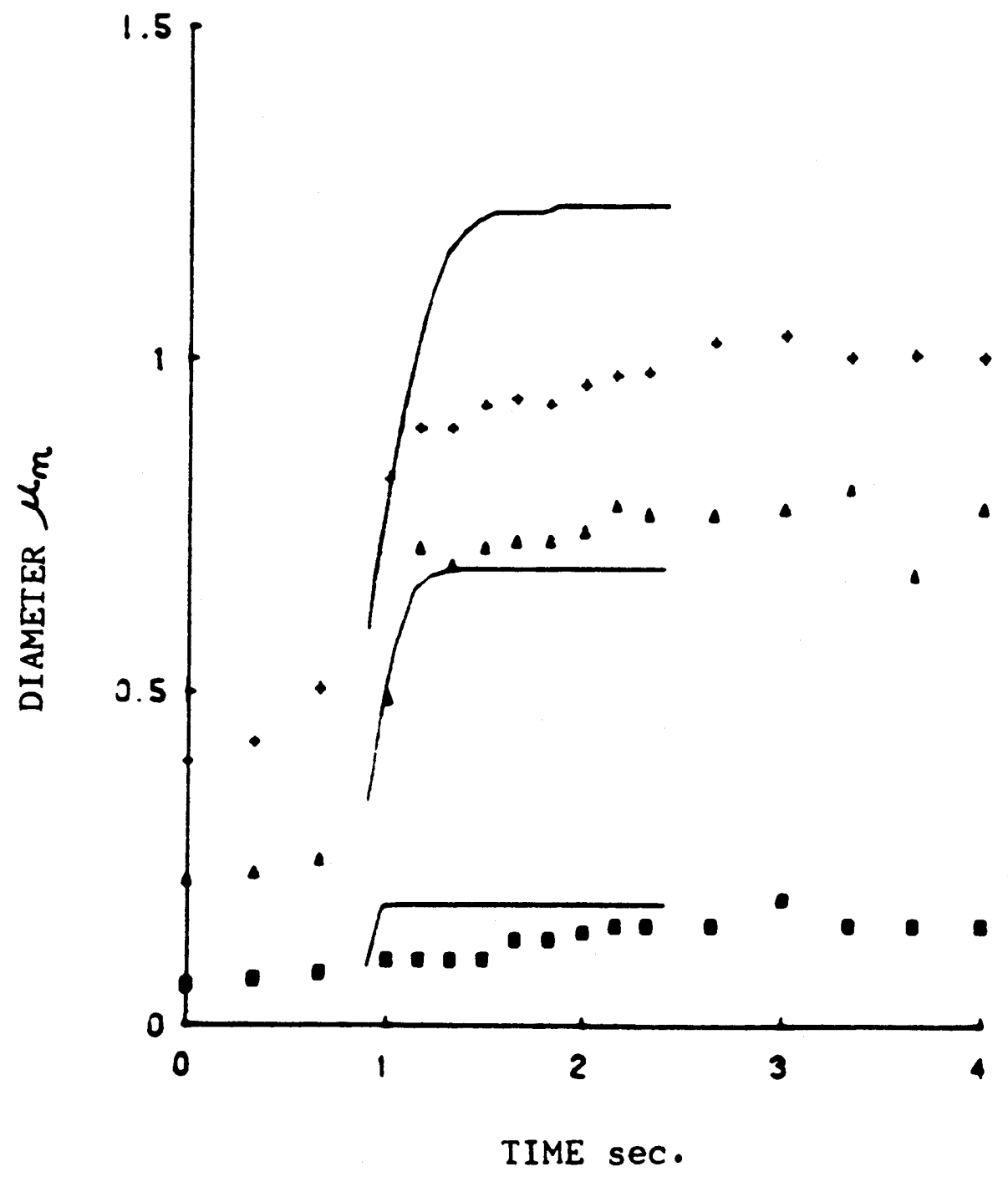

Elgure 11. Computer simulated hydration curves for the particles in Figure 7 . 
experimentally observed. The experimentally measured final droplet diameter indicates that hydration pressure was less than 88.08 relative humidity. The simulated hydration curve for particle 1 shows a very good fit to the experimental data. The particles in Table IV, Figure 8 were simulated using $\mathrm{H}=79.5$ and an accommodation coefficient of $1.5 \times 10^{-4}$ (Figure 1 ). Once again, the computer simulated hydration curves show a very good fit to the experimental data.

The above analysis of sodium chloride hydration data suggested that smaller accommodation coefficients are appropriate for small particles, thus it was decided to obtain hydration data using very small pressure gradients in an attempt to determine if thermodynamic or kinetic effects were dominant in the initiation of hydration. Since very small pressure gradients were used, the growth rates of the droplets were much slower and no attempt was made to allow the droplet to grow to a final diameter. An effort was made simply to observe if small particles hydrated before, after or at the same time as larger particles. Thermodynamic effects, the Kelvin solubility equation, predicts that small particles should hydrate first since they are in equilibrium with a higher salt concentration producing greater vapor pressure lowering. However, the experimental data which was kinetically analyzed using the computer simulated hydration curves 


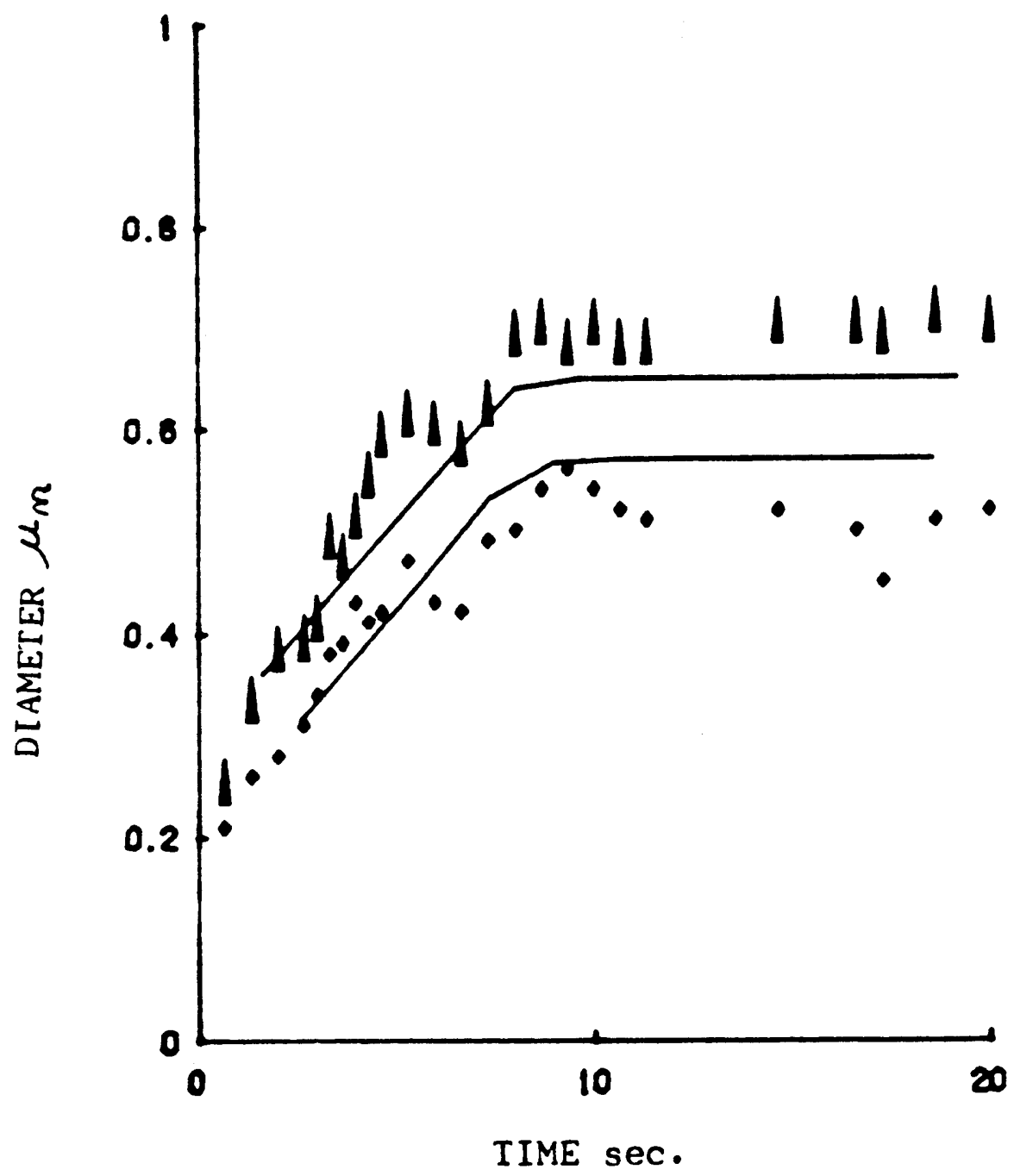

Flgure 12. Computer simulated hydration curves for the particles in Figure 8 . 
indicate that the accommodation coefficient is indeed dependent upon particle size and that small particles have smaller accommodation coefficients. If the accommodation coefficient were sufficiently small, growth of the droplet would be extremly slow and a negligible growth would occur in the droplet even at hydration pressure. A perceptible growth in the droplet would not occur until sufficient time had passed for the droplet to grow to a point where the accommodation coefficient was larger and the rate of hydration was thus increased.

The Kelvin solubility and size dependence of the accommodation coefficient have opposing effects on the observable initiation of hydration for small particles. In a more quantitative analysis zung (27) states, "...one sees that the Gibbs-Thompson correction for small droplets remains negligible except for droplets having a radius less than $10^{-1} \mathrm{~cm}$." Four trials were run to observe the onset of hydration relative to particle size. Hydration and dehydration data obtained during these 4 trials are tabulated in Tables $V$ through $X$ and graphically represented in Figures 13 through 18. In trial 1 (Table V, Figure 13), particle 2 , with a length of $0.234 \mu$, was observed to hydrate first. Particles both smaller and larger than particle 2 hydrated subsequent to particle 2 . In Trial 2 (Table VI, Figure 14), the largest particle, particle 1 with $\mathrm{L}=1.034 \mu$, was observed to hydrate first. 
TABLE V

EXPERIMENTAL DATA-TRIAL 1

$\begin{array}{lllllll}\text { TIME } & \text { \#1 } & \text { \#2 } & \text { \#3 } & \text { \#4 } & \text { \#5 } & \text { \#6 } \\ 0.016 & 0.134 & 0.234 & 0.25 & 0.199 & 0.314 & 0.339 \\ 0.333 & 0.139 & 0.284 & 0.25 & 0.209 & 0.309 & 0.339 \\ 0.666 & 0.179 & 0.419 & 0.25 & 0.214 & 0.309 & 0.334 \\ 1.000 & 0.179 & 0.419 & 0.309 & 0.214 & 0.309 & 0.364 \\ 1.333 & 0.194 & 0.444 & 0.329 & 0.224 & 0.309 & 0.394 \\ 1.666 & 0.199 & 0.449 & 0.329 & 0.224 & 0.324 & 0.394 \\ 2.000 & 0.199 & 0.449 & 0.329 & 0.224 & 0.324 & 0.394 \\ 2.333 & 0.199 & 0.449 & 0.329 & 0.229 & 0.324 & 0.394\end{array}$


TABLE VI

\section{EXPERIMENTAL DATA-TRIAL 2}

TIME 非 \#2 \#3 \#4

$\begin{array}{lllll}0.016 & 1.034 & 0.839 & 0.314 & 0.364 \\ 0.166 & 1.029 & 0.839 & 0.319 & 0.364 \\ 0.333 & 1.039 & 0.844 & 0.324 & 0.364 \\ 0.500 & 1.039 & 0.834 & 0.339 & 0.364 \\ 0.666 & 1.049 & 0.839 & 0.339 & 0.375 \\ 0.833 & 1.074 & 0.844 & 0.339 & 0.384 \\ 1.000 & 1.219 & 0.849 & 0.339 & 0.389 \\ 1.166 & 1.294 & 0.854 & 0.354 & 0.389 \\ 1.333 & 1.494 & 0.864 & 0.375 & 0.389 \\ 1.500 & 1.694 & 0.864 & 0.389 & 0.389 \\ 1.666 & 1.699 & 0.889 & 0.394 & 0.389 \\ 1.833 & 1.764 & 0.954 & 0.399 & 0.389 \\ 2.000 & 1.799 & 1.079 & 0.399 & 0.389 \\ 2.166 & 1.819 & 1.094 & 0.399 & 0.389 \\ 2.333 & 1.854 & 1.094 & 0.399 & 0.389 \\ 2.500 & 1.875 & 1.094 & 0.399 & 0.389 \\ 2.666 & 1.875 & 1.094 & 0.399 & 0.389 \\ 2.833 & 1.875 & 1.094 & 0.399 & 0.389\end{array}$


TABLE VII

EXPERIMENTAL DATA

TRIAL 2 DEHYDRATION

$\begin{array}{lcc}\text { TIME } & \# 1 & \# 2 \\ 0.016 & 1.875 & 1.094 \\ 0.033 & 1.774 & 0.889 \\ 0.049 & 1.599 & 0.734 \\ 0.066 & 1.004 & 0.614 \\ 0.083 & 0.974 & 0.614 \\ 0.099 & 0.974 & 0.614\end{array}$


TABLE VIII

EXPERIMENTAL DATA-TRIAL 3

TIME \#1 \#2 \#3 \#4 \#5 \#1 \#6 \#7

$\begin{array}{llllllll}0.016 & 0.159 & 0.364 & 0.319 & 0.164 & 0.250 & 0.384 & 0.234\end{array}$ $\begin{array}{lllllllll}0.333 & 0.154 & 0.375 & 0.319 & 0.164 & 0.250 & 0.384 & 0.334\end{array}$ $\begin{array}{lllllllll}0.666 & 0.159 & 0.364 & 0.319 & 0.159 & 0.250 & 0.389 & 0.384\end{array}$ $\begin{array}{llllllll}1.000 & 0.154 & 0.369 & 0.319 & 0.224 & 0.279 & 0.389 & 0.389\end{array}$

$\begin{array}{llllllll}1.333 & 0.164 & 0.404 & 0.319 & 0.229 & 0.289 & 0.409 & 0.419\end{array}$ $\begin{array}{lllllllll}1.666 & 0.174 & 0.424 & 0.319 & 0.224 & 0.284 & 0.404 & 0.434\end{array}$ $\begin{array}{llllllll}2.000 & 0.169 & 0.424 & 0.334 & 0.224 & 0.284 & 0.399 & 0.434\end{array}$ $\begin{array}{llllllll}2.333 & 0.179 & 0.449 & 0.334 & 0.234 & 0.299 & 0.424 & 0.444\end{array}$ $\begin{array}{lllllllll}2.666 & 0.184 & 0.449 & 0.349 & 0.234 & 0.299 & 0.424 & 0.444\end{array}$ $\begin{array}{llllllll}3.000 & 0.184 & 0.449 & 0.354 & 0.250 & 0.299 & 0.424 & 0.444\end{array}$ $\begin{array}{llllllll}3.333 & 0.184 & 0.449 & 0.354 & 0.244 & 0.299 & 0.424 & 0.444\end{array}$ $\begin{array}{llllllll}3.666 & 0.184 & 0.449 & 0.354 & 0.244 & 0.299 & 0.424 & 0.444\end{array}$ $\begin{array}{llllllll}4.000 & 0.184 & 0.449 & 0.354 & 0.244 & 0.299 & 0.424 & 0.444\end{array}$ $\begin{array}{llllllll}4.333 & 0.184 & 0.449 & 0.354 & 0.244 & 0.299 & 0.424 & 0.444\end{array}$ $\begin{array}{llllllll}4.666 & 0.184 & 0.449 & 0.354 & 0.244 & 0.299 & 0.424 & 0.444\end{array}$ $\begin{array}{llllllll}5.000 & 0.184 & 0.454 & 0.354 & 0.244 & 0.299 & 0.424 & 0.444\end{array}$ $\begin{array}{lllllllll}5.333 & 0.184 & 0.454 & 0.354 & 0.244 & 0.299 & 0.424 & 0.444\end{array}$ $\begin{array}{llllllll}5.666 & 0.184 & 0.454 & 0.354 & 0.244 & 0.299 & 0.424 & 0.444\end{array}$ $\begin{array}{llllllll}6.000 & 0.184 & 0.454 & 0.354 & 0.244 & 0.299 & 0.424 & 0.444\end{array}$ $\begin{array}{llllllll}6.333 & 0.184 & 0.454 & 0.354 & 0.250 & 0.314 & 0.424 & 0.444\end{array}$ $\begin{array}{llllllll}6.666 & 0.199 & 0.514 & 0.384 & 0.250 & 0.319 & 0.434 & 0.444\end{array}$ $\begin{array}{llllllll}7.000 & 0.199 & 0.514 & 0.384 & 0.250 & 0.319 & 0.434 & 0.444\end{array}$ $\begin{array}{llllllll}7.333 & 0.199 & 0.524 & 0.384 & 0.259 & 0.319 & 0.429 & 0.444\end{array}$ $\begin{array}{llllllll}7.666 & 0.199 & 0.534 & 0.384 & 0.274 & 0.319 & 0.429 & 0.444\end{array}$ $\begin{array}{llllllll}8.000 & 0.199 & 0.539 & 0.389 & 0.274 & 0.314 & 0.429 & 0.444\end{array}$ 
TABLE IX

EXPERIMENTAL DATA

TRIAL 3 DEHYDRATION

$\begin{array}{cccc}\text { TIME } & \# 1 & \# 2 & \text { \#3 } \\ 0.016 & 0.549 & 0.314 & 0.434 \\ 0.333 & 0.524 & 0.314 & 0.424 \\ 0.666 & 0.459 & 0.319 & 0.419 \\ 1.000 & 0.434 & 0.289 & 0.424 \\ 1.333 & 0.399 & 0.279 & 0.404 \\ 1.666 & 0.389 & 0.284 & 0.379 \\ 2.000 & 0.369 & 0.284 & 0.384 \\ 2.333 & 0.369 & 0.264 & 0.384 \\ 2.666 & 0.369 & 0.254 & 0.384 \\ 3.000 & 0.369 & 0.250 & 0.384\end{array}$


TABLE X

EXPERIMENTAL DATA-TRIAL 4

$\begin{array}{lllll}\text { IIME } & \# 1 & \# 2 & \# 3 & \# 4 \\ 0.016 & 0.524 & 0.089 & 0.604 & 0.189 \\ 0.166 & 0.524 & 0.089 & 0.604 & 0.184 \\ 0.333 & 0.524 & 0.119 & 0.604 & 0.184 \\ 0.500 & 0.594 & 0.144 & 0.609 & 0.189 \\ 0.666 & 0.609 & 0.144 & 0.604 & 0.184 \\ 0.833 & 0.609 & 0.149 & 0.604 & 0.184 \\ 1.000 & 0.604 & 0.169 & 0.604 & 0.184 \\ 1.166 & 0.614 & 0.169 & 0.604 & 0.184 \\ 1.333 & 0.609 & 0.169 & 0.604 & 0.184 \\ 1.500 & 0.664 & 0.174 & 0.604 & 0.184 \\ 1.666 & 0.709 & 0.179 & 0.609 & 0.189 \\ 1.833 & 0.724 & 0.229 & 0.625 & 0.189 \\ 2.000 & 0.724 & 0.229 & 0.639 & 0.189 \\ 2.166 & 0.729 & 0.274 & 0.684 & 0.224 \\ 2.333 & 0.739 & 0.324 & 0.699 & 0.250 \\ 2.500 & 0.734 & 0.324 & 0.699 & 0.250 \\ 2.666 & 0.739 & 0.319 & 0.699 & 0.319 \\ 2.833 & 0.734 & 0.324 & 0.699 & 0.339 \\ 3.000 & 0.734 & 0.324 & 0.699 & 0.339 \\ 3.166 & 0.734 & 0.324 & 0.699 & 0.339 \\ 3.333 & 0.734 & 0.324 & 0.699 & 0.339\end{array}$




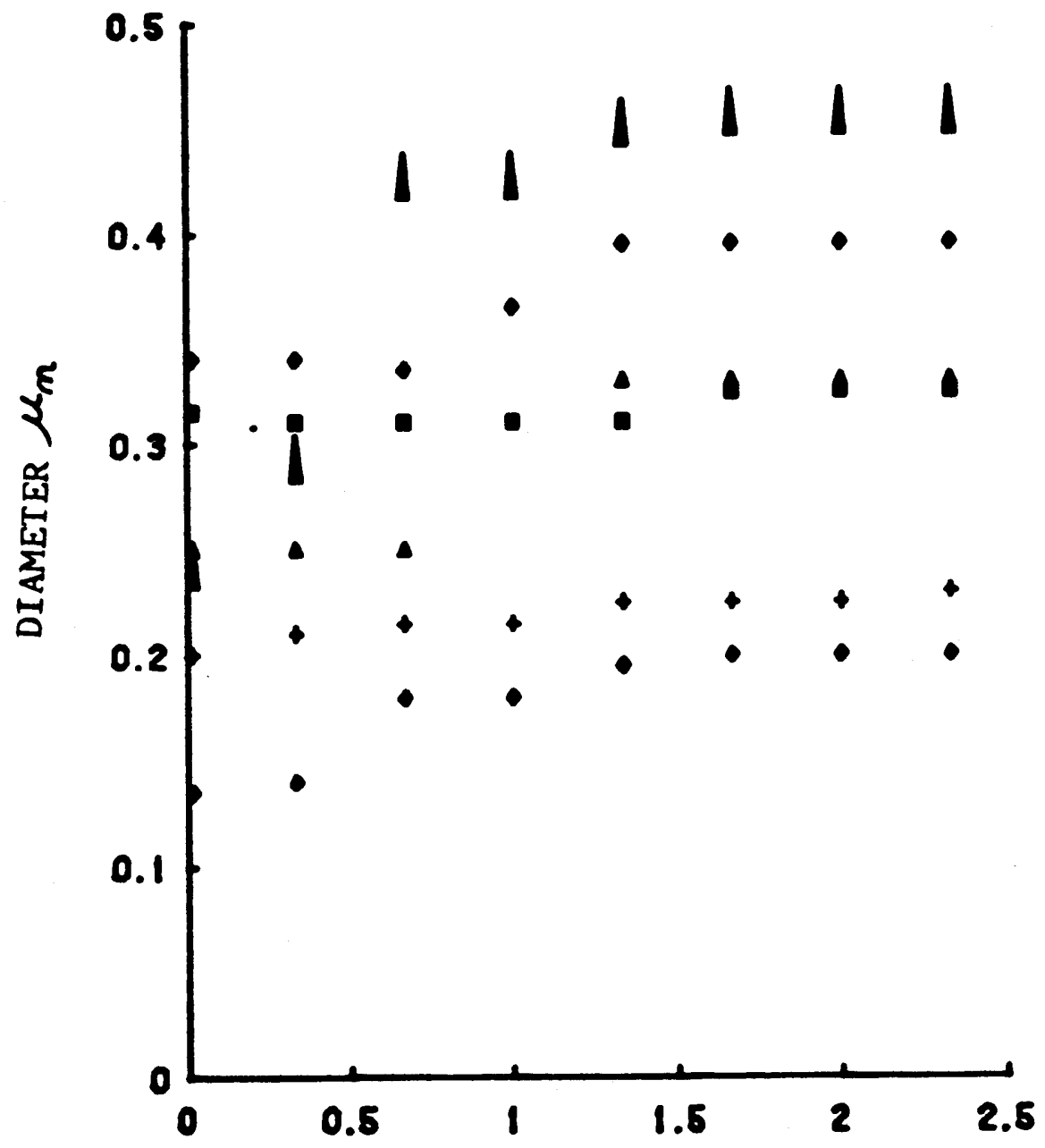

TIME sec.

Fisure 13. Graphic representation of data in Table $V$. 


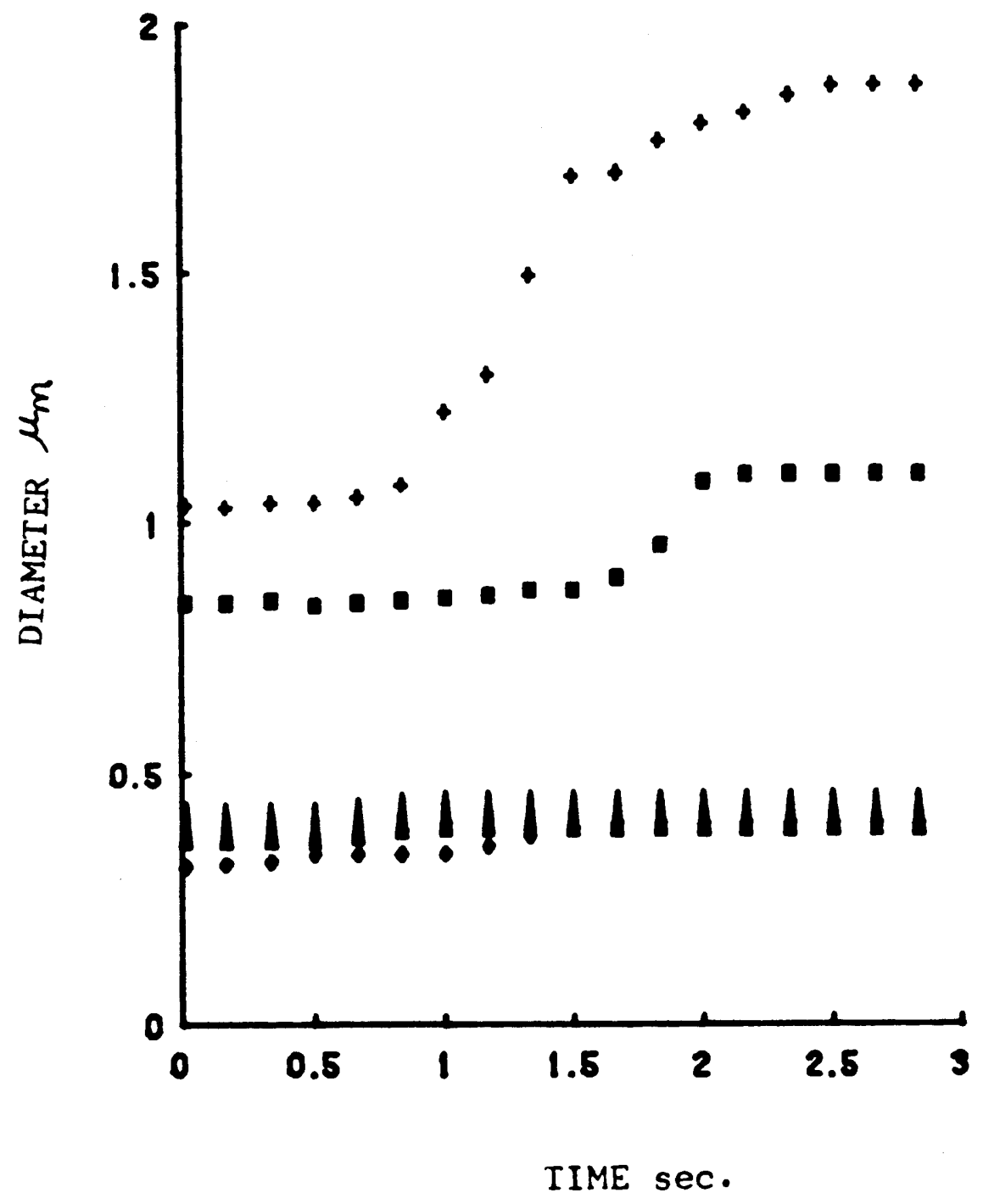

Figure 14. Graphic representation of data in Table VI. 


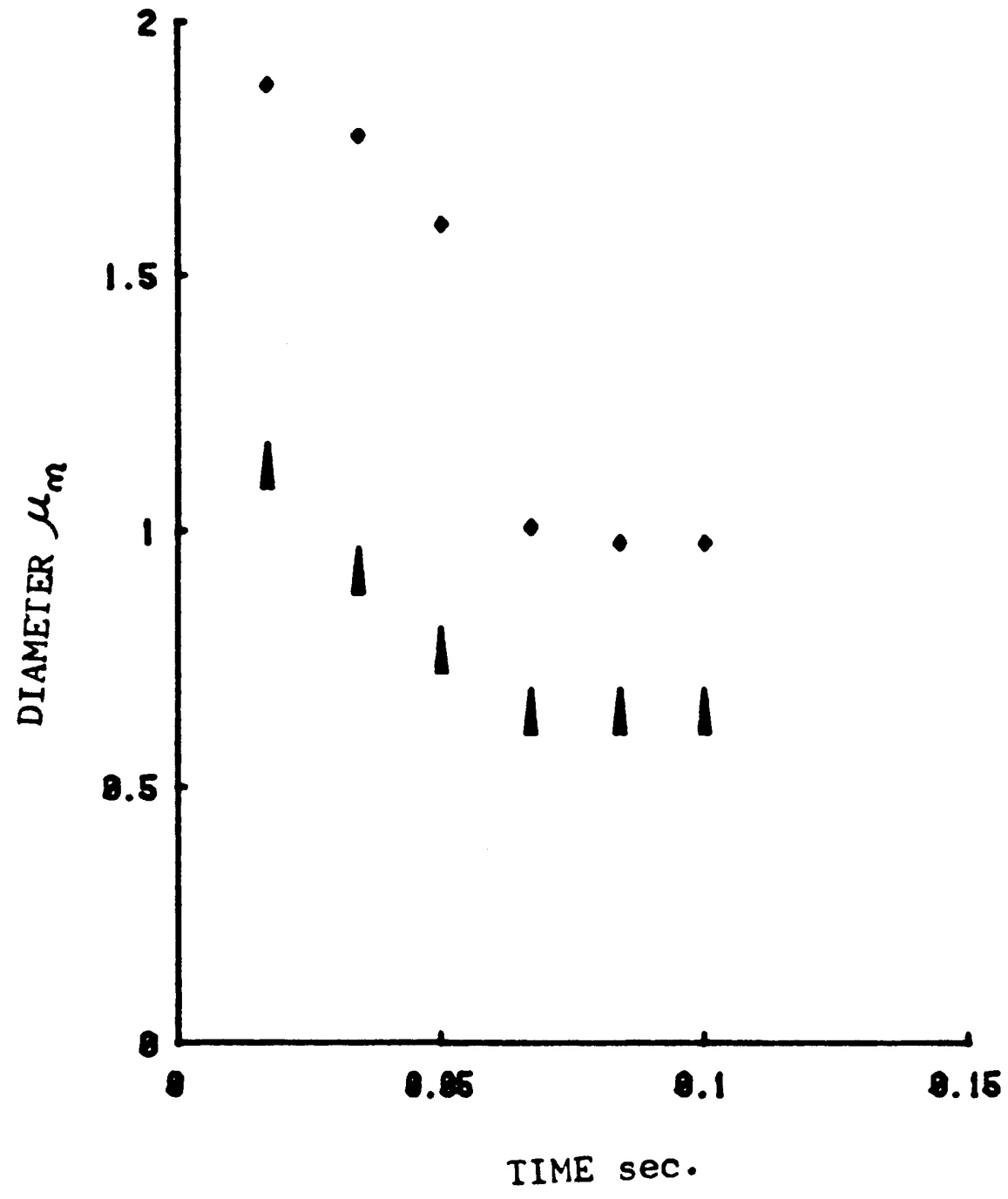

Flgure 15. Graphic representation of data in Table VII. 


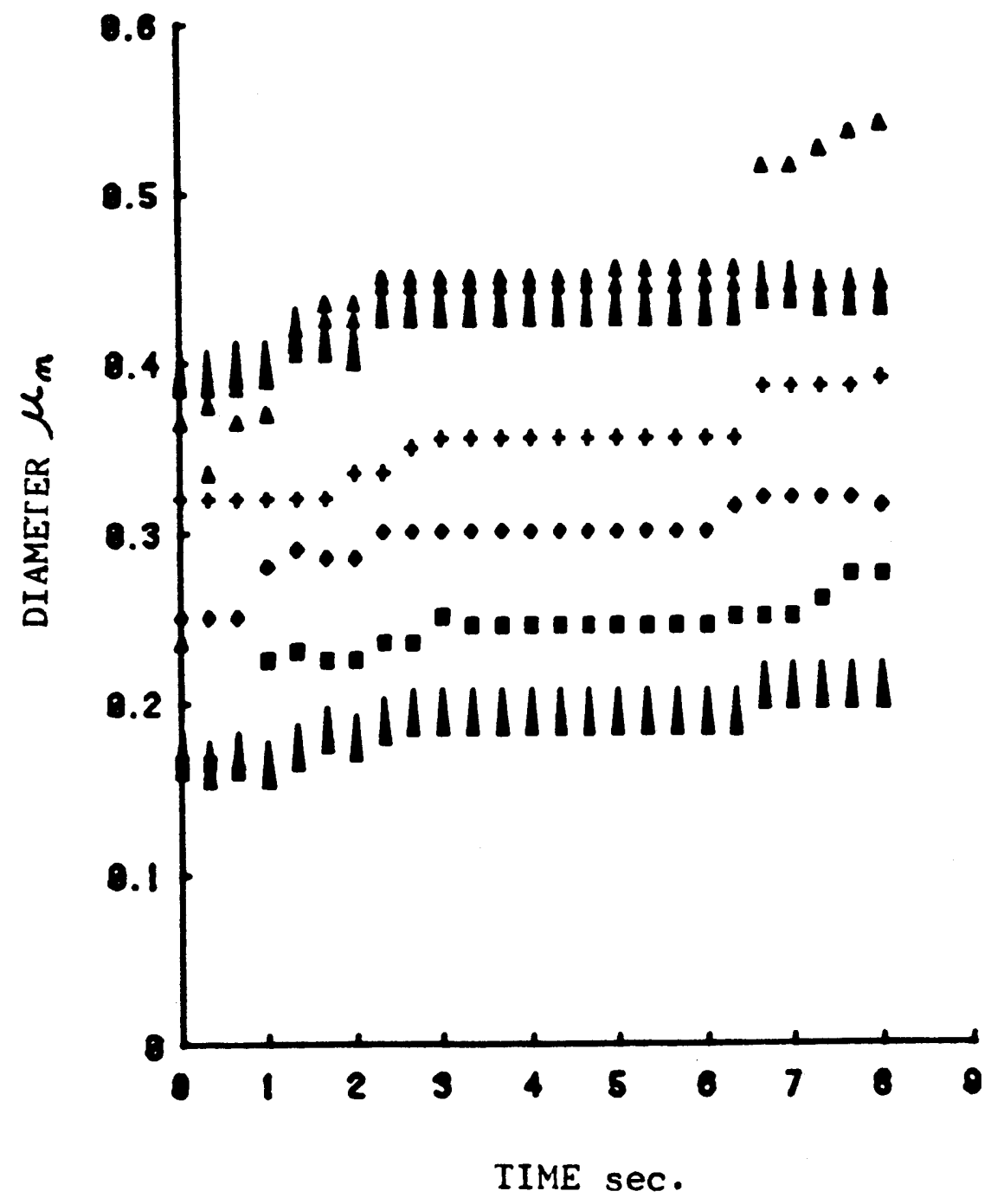

Figure 16. Graphic representation of data in Iable VIII. 


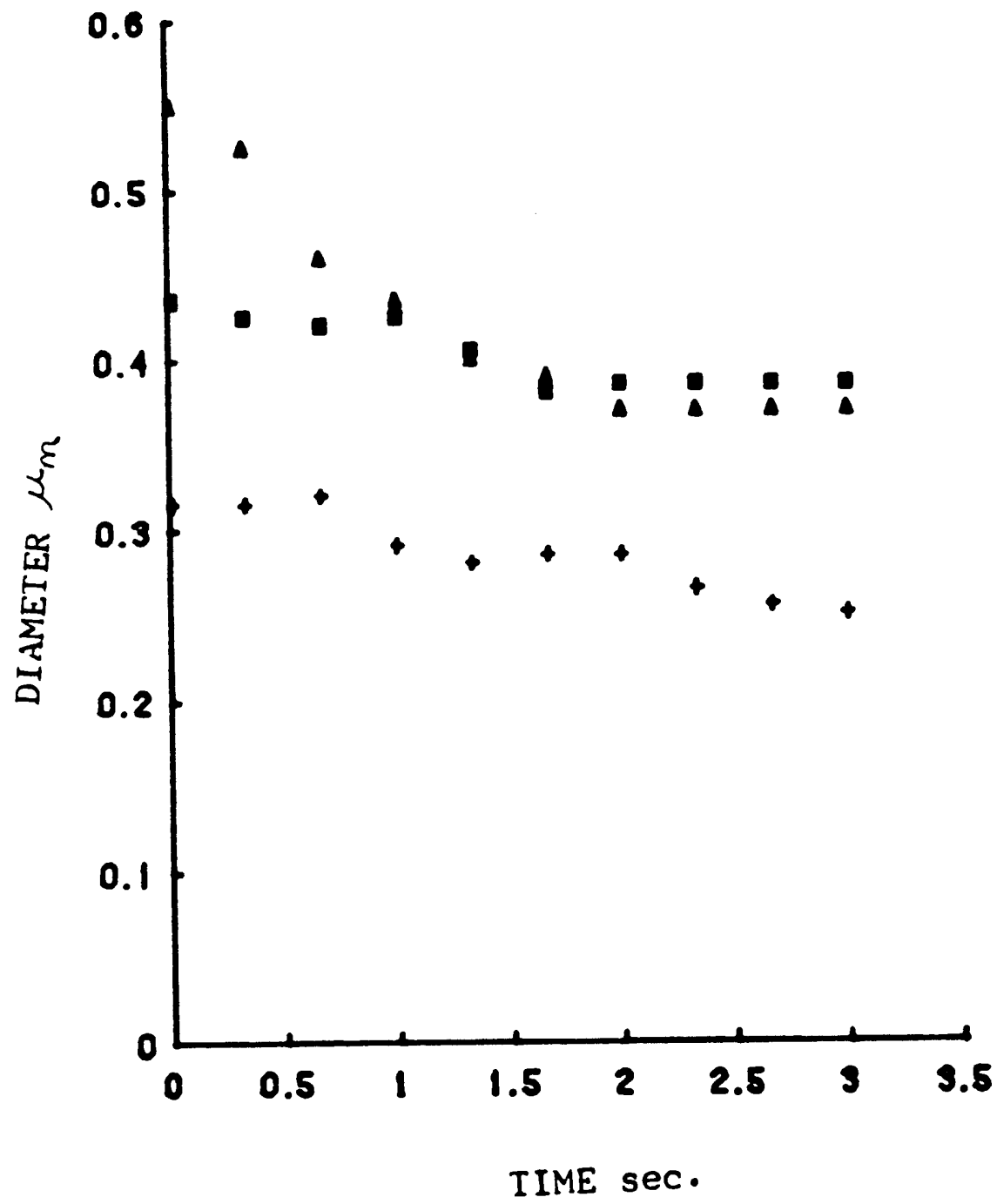

Eigure 17. Graphic representation of data in Table IX. 


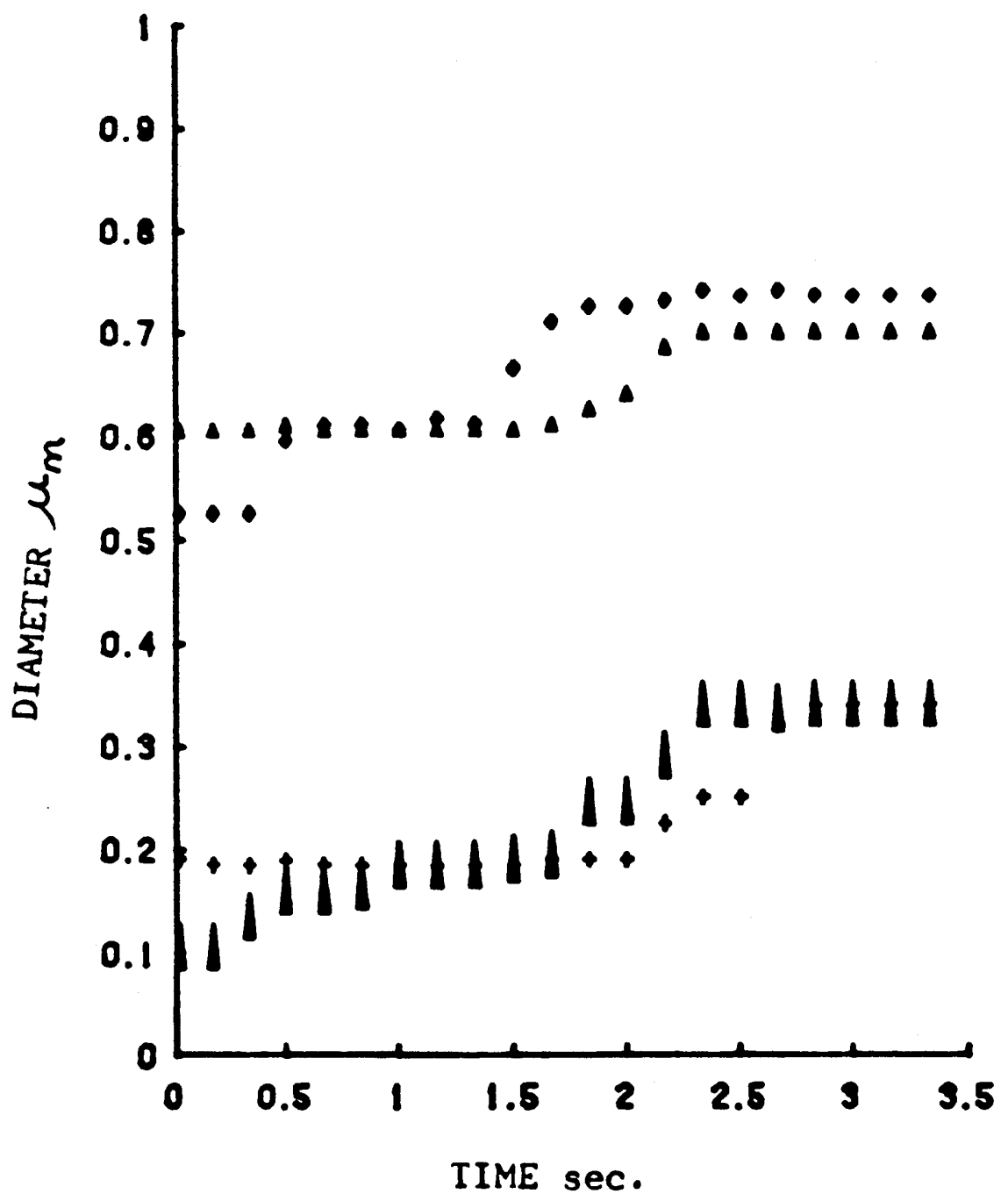

Eigure 18. Graphic representation of data in Table $X$. 
Dehydration measurements on particles 1 and 2 (Table VII, Figure 15), show no significant difference in the onset of dehydration. In trial 3 (Table VIII, Figure 16), onset of hydration was nearly simultaneous for all particles except patrticle 3 which hydrated somewhat later than the other particles. Once again, particles both larger and smaller than particle 3 were observed. Dehydration measurements on particles 2, 5 and 6 (Table IX, Figure 17), illustrate that the largest particle, particle 2, $D=0.549 \mu$, dehydrated before the smaller particles. Trial 4 (Table $\mathrm{X}$, Figure 18), once again gave no consistent pattern for particle size versus onset of hydration. These inconsistencies may be explained by the presence of artifact or contamination of the sodium chloride. However, as Figures 7 and 14 clearly show, the hydration rate of smaller particles is slower. This is consistent with the prediction that the accommodation coefficient is in fact surface dependent and that small particles have smaller accommodation coefficients. Furthermore, the fact that small particles were not observed to consistantly hydrate before larger particles is also in agreement with zung's (27) prediction that the Kelvin effects are neglible for droplets larger than $0.001 \mu$. Thus, though the Kelvin solulility considerations alone predict small particles will hydrate first, this was not observed to happen. 
CHAPTER V

CONCLUS IONS

Correlation of the experimental data with the computer simulated hydration curves indicates that the theoretical model proposed in this thesis may be used to reasonably predict sodium chloride hydration rates. However, more complete information on dehydrataion conditions leading to crystal shattering is needed to accurately predict the thermodynamic explanation for such shattering since, as has been noted, the Kelvin solubility effect and surface dependence of the accommodation coefficient have opposing effects. The experimental data presented also give insight into the thermodynamic versus kinetic effects of particle size on hydration. These data are in qualitative agreement with the kinetic versus thermodynamic predictions of zung (27). No other experimental data testing this prediction could be found.

Changes in the experimental apparatus would improve the accuracy of experimental data. One such change would be modification of the environmental cell design to optimize image resolution. Accurate pressure measurements during hydration would also be of value. 
Though improvements can and should be made in the gathering of quantitative experimental results, the work presented in this thesis has illustrated that the theoretical model as written is a useful tool in predicting sodium chloride hydration curves. 
REFERENCES

1. Twomey, S. and K. N. McMaster 1955. "The Production of Condensation Nuclei by Crystallizing Salt Particles," Tellus, 7, 458-461.

2. Koehler, Hilding 1936. "The Nucleus in and the Growth of Hygroscopic Droplets," Faraday Society London Transactions, $32 \mathrm{pt} .2$, 1152-1161.

3. LaMer, Victor $K$. and Ruth Gruen 1952. "A Direct Test of Kelvin's Equation Connecting Vapor Pressure and Radius of Curvature," Faraday Society London Transactions, 48, 410-415.

4. Dessens, Henri 1949. "The Use of Spiders Threads in the Study of Condensation Nuclei," Ouarterly Journal of the Royal Meteorological Society, 75, 23-27.

5. Howell, Wallace E. 1949. "The Growth of Cloud Drops in Uniformly Cooled Air," Journal of Meteorology, 6 , 134-149.

6. Keith, C. H. and A. B. Arons 1954. "The Growth of Seasalt Particles by Condensation of Atmospheric Water Vapor," Journal of Meteorology, 11 . 173-184.

7. Twomey, S. 1953. "The Identification of Individual Hygroscopic Particles in the Atmosphere by a Phase-Transition Method," Journal of Applied Physics, 24 no. 9, 1099-1102.

8. Orr, Clyde Jr., Kenneth Hurd, and William J. Corbett 1948. "Aersol Size and Relative Humidity," Journal of Colloid Science, 13, 472-482.

9. Dennis, W. L. 1960. "The Growth of Hygroscopic Drops 
in a Humid Air Stream," Faraday Society Discussions, 30, 78-85.

10. Covert, D. S., R. J. Charlson and N. C. Ahlquist 1972. "A Study of the Relationship of Chemical Composition and Humidity to Light scattering by Aerosols," Journal of Applied Meteorology, 11, 968-976.

11. Tang, I. N. 1976. "Phase Transformation and Growth of Aerosol Particles Composed of Mixed Salts," Journal of Aerosol Science, 7, 361-371.

12. Cooper, Douglas W., R. Lee Byers, and John W. Davis 1973. "Measurements of Laser Light Backscattering vs. Humidity for Salt Aerosols." Environmental Science and Technology, 7, 142-147.

13. Wright, H. L. 1939. "Atmospheric Opacity of Valentia," Quarterly Journal of the Royal Meteorological Society, 66, 66-77.

14. Brown, J. J., K. M. Cook, F. G. Ney and Theodore Hatch 1950. "Influence of Particle Size Upon the Retention of Particulate Matter in the Human Lung," American Journal of Public Health, 40 , 450-458.

15. Held, Joann L. and Douglas W. Cooper 1979. "Theoretical Investigation of the Effects of Relative Humidity on Aerosol Respirable Fraction," Atmospheric Environment, 13, 1419-1425.

16. Cinkotai, F. F. 1971. "The Behavior of Sodium Chloride Particles in Moist Air," Aerosol Science, 2, 219-223.

17. Chang, Wei and D. F. Parsons 1974. "Use of an electron Microscope Hydration Chamber to Study Condensation Problems," Journal of Microscopy, $102 \mathrm{pt} .2,219-223$. 
Measurement of Drop Size and Liquid Water Content of Fogs and Clouds," Papers in Physical oceanography and Meteorology, 6 no. 4, 3-31.

19. Keng, Edward Y. H. 1970. "Gaseous Impurities and Nuclear Condensation on Airborne Sodium Chloride Particles," Environmental Science and Technology, 4, 417-420.

20. Brunauer, Stephen, P. H. Emmett and Edward Teller 1938. "Adsorption of Gases in Multimolecular Layers," American Chemical Society Journal, 60, 309-319.

21. Barraclough, P. B. and P. G. Hall 1974. "The Adsorption of Water Vapour by Lithium Fluoride, Sodium Fluoride and Sodium Chloride," Surface Science, 46, 393-417.

22. Adamson, Arthur W. 1976. Physical Chemistry of Surfaces, John Wiley \& Sons.

23. Friedlander, S. K. 1977. Smoke, Dust and Haze, John Wiley \& Sons.

24. Gleeson, George W. 1938. "Some Simple Experiments Dealing with Rates of Solution," Journal of Chemical Education, 15, 187-190.

25. M. W. Kellogg Company, July 1965. Saline Water Conversion Engineering Data Book, United States Department of the Interior.

26. Davies, C. N. 1978. Fundamentals of Aerosol Science, Chpt. 3, "Evaporation of Airborne Droplets," D. T. Shaw ed. Wiley \& Sons

27. Zung, Joseph T. 1975. "Surface and Gas-Phase Resistances to the Evaporation of Droplets," Environmental Letters, 8 (4), 283-296.

28. Dinger, J. E. , H. B. Howell and T. A. Wojciechowski 
1970. "On the Source and Composition of Cloud Nuclei in a Resident Air Mass over the North Atlantic," Journal of the Atmospheric Sciences, $27,791-797$.

29. Radke, L. F. and D. Hegg 1972. "The Shattering of Saline Droplets Upon Crystallization," Journal De Research Atmospherique. no. 1\&2. 447-455.

30. Lodge, James P. and Ferdinand Baer 1954. "An Experimental Investigation of the Shattering of Salt Particles on Crystallization." Journal of Meteorology, 11, 420-421.

31. Blanchard, Duncan C. and A. Theodore Spencer 1964. "Condensation Nuclei and the Crystallization of Saline Drops," Journal of the Atmospheric Sciences, 21, 182-186.

32. Adamson, Arthur W. 1976. A Textbook of Physical Chemistry, Academic Press.

33. Glasstone, Samuel. 1972. Thermodynamics for Chemists, Robert E. Krieger Publishing Company.

34. Clarke, Antony D. 1978. An Assessment of the Transmission Electron Microscope for the Study of Aerosol-Gas Interactions: Direct Observation of Sodium Chloride Hydration Phenomena. Masters Thesis in Physics, P, S. U.

35. Fullam Peter W. October 16, 1981. Letter from Ernest F. Fullam Inc. Schenectady, New York.

36. Frisch, H. L., and Collins, F. C. 1953. "Diffusional Processes in the Growth of Aerosol Particles. II, "Journal of Chemical Physics, 21, 2158-2165.

37. Ternus, Larry. August 4, 1981. Personal Communication. 
38. Weast, Robert C. ed. 1974. Handbook of Chemistry and Physics, 54th Edition. CRC Press

39. Robinson, R. A. and R. H. Stokes 1968. Electrolyte Solutions (2nd Rev. Ed.), Butterworths, London

40. National Research Council, 1933. International

Critical Tables of Numerical Data, Physics, Chemistry and Technology. McGraw-Hill. 


\section{APPENDIX A}

\section{SALT IMPACTION}

The $2.3 \mathrm{~mm} 400$ mesh electron microscope grids or wet cell windows on which the salt particles were deposited can be purchased from Ernest F. Fullam Inc. In the manufacture of these wet cell windows formvar is first applied over the copper mesh, then collodian (nitrocellulose) then sio (35). Thus, the salt particles rest on a surface of SiO. This three layer film exists on the shiny side of the grid only. Six of these grids (with the shiny side up) are placed in the darkened holes in the Anderson-type cascade impactor electron microscope grid holder (numbers 10-12 of Fig. 19). The remaining stages of the impactor are then put in place making sure the alignment mark on stage 10 is aligned with the handle of stage 12. The wing nut on the top of the impactor is then tightened to secure the stages.

The devilbiss nebulizer must then be charged and prepared for operation. A 0.04258 by weight solution of AR grade $\mathrm{NaCl}$ in deionized water (purified by a Barnstead nanopure system) was used to charge the devilbiss nebulizer. The solution was introduced through the tygon 

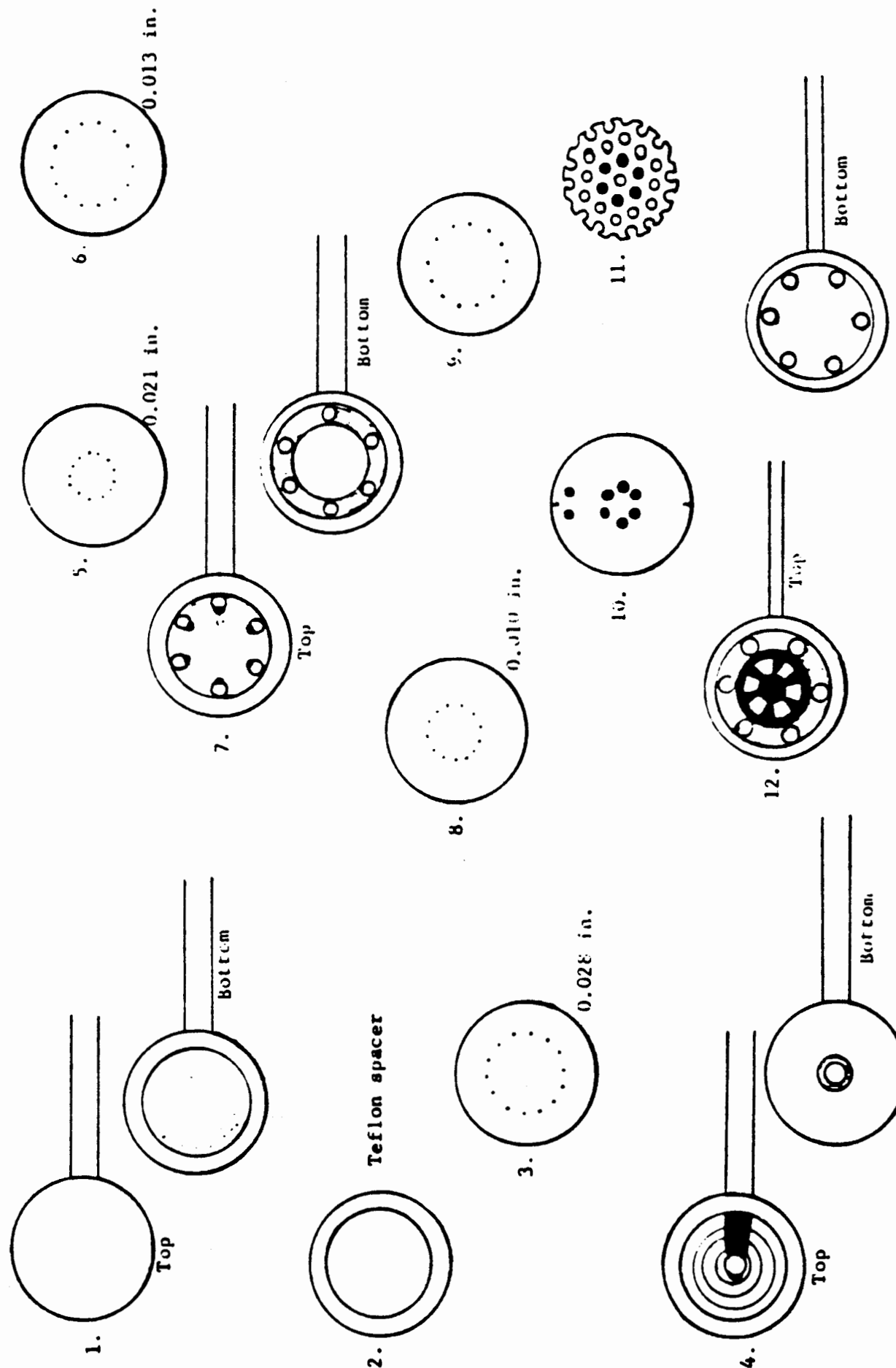
tubing bleed line and was allowed to flow into the bulb of the nebulizer(see Fig. 2).

A modification of a technique described by Larry Ternus (37) which he found to generate particles from $0.005 \mu$ to $6.50 \mu$ was used for deposition of salt particles onto the $2.3 \mathrm{~mm} 400$ mesh wet cell windows.

Impaction technique:

1. The impactor was assembled in the following manner from bottom to top using the numbers of the pieces as shown in Fig. $19: 2,12,11$, six new grids which are to have salt deposited on them (placed in the darkened holes in piece 11), 2, $10,2,9,2,4,2,8,2,7,2,6,2,4,2,5,2$, $4,2,3,2,1$, wing nut (which is tightened to finger tight to secure the pieces. The holes in the handles of pieces 4,7 and 12 were securely plugged with teflon stoppers. A hot air blower was used to preheat the modified Anderson cascade impactor to approximately 50 degrees centigrade to attain dessication of the aerosol droplets generated by the devilbiss nebulizer prior to impaction. This procedure also significantly reduces amorphous crystals (34).

2. Using a water displacement method the flow rate of the dry nitrogen carrier gas was adjusted to $4000 \mathrm{ml} / \mathrm{min}$.

3. Pinch clamp $A$ on the nebulizer was opened. With pinch clamp B closed and the valve closed, the nebulizer was 
connected to the dry nitrogen carrier gas.

4. With the bleed line opened (pinch clamp B opened) the valve on the nebulizer was opened and the bypass clamp was shut. The system was allowed to flush out for several seconds and then connected to the handle of piece 1 of the impactor.

5. The bleed line was closed for three seconds, and then opened for three seconds. This pulsing was done three times to provide a nine second impaction time.

6. The grids were rotated approximately one degree and steps two through four were repeated. Rotating the grids improves particle location on the grid-a deposition in the center of the grid is reguired.

7. The grids were observed under a light microscope to assure a central deposition of salt particles (though only the larger particles could be seen).

8. The above procedure was repeated using a diluted solution of Dow latex particles. According to the manufacturer these particles were $0.0917 \mu$ in diameter with a standard deviation of $0.0058 \mu$ (206 measurements). These particles were used for size calibration.

9. If the grids looked suitable they were stored in a dessicator until they were needed. 
10. The impactor was taken apart and rinsed several times with tap water and then at least three to five times with distilled or purified water. 


\section{APPENDIX B}

COMPUTER MODEL

This program (Table XI) was written in basic for use on a Honeywell computer. The following is the list of symbols which were used in the development of this program:

Fl=flux of water in moles/sec F2=flux of sodium chloride in moles/sec M2=molecular weight of sodium chloride, M2=58.45 $/ \mathrm{mole}$

$\mathrm{Ml}=$ molecular weight of water, $M 1=18.0152 \mathrm{~g} / \mathrm{mole} \mathrm{(39)}$ $\mathrm{K} 2$ =rate constant for the flux of sodium chloride, $\mathrm{K} 2=2.14 \times 10^{-3} \mathrm{~cm} / \mathrm{sec}$

$D=$ diameter of the droplet Sl=surface area of the droplet, $S I=0.68(\mathrm{PI}) \mathrm{D}^{2}(34)$ $L=$ length of the salt cube of any time $T$ L0=original length of salt cube, prior to any hydration. S2=available surface area of the cubic sodium chloride crystal. Since one face of the cube sits on the grid and is therefore assumed to be unavailable for water molecule collision $S 2=5 \times L^{2}$. $\mathrm{C} 3=$ solubility of bulk sodium chloride at $25^{\circ} \mathrm{C}$, 


\section{TABLE XI}

COMPUTER PROGRAM FOR INTEGRATION OF SODIUM CHLORIDE HYDRATION EQUATIONS WITH KELVIN CONSIDERATIONS

1000 REM INTEGRATION FOR A REAL SOLUTION WITH KELVIN

1001 REM CONSIDERATIONS

1010 REM INITIAL CONDITIONS

1020 L $0=0.5$

$1030 \mathrm{~L} 0=\mathrm{L} 0 / 10000$

$1040 \quad D=1.37$

$1050 \mathrm{D}=\mathrm{D} / 10000$

1060 REM CONSTANTS OR INITIAL CALCULATIONS

1070 REM SUBSCRIPT I REFERS TO WATER

1080 REM SUBSCRIPT 2 REFERS TO SODIUM CHLORIDE

$1090 \quad C 3=0.3179$

$1091 \quad A 7=.003$

1100 P0 $=1.2772 \mathrm{E}-6$

$1110 \quad F=0.758$

$1120 \mathrm{R}=8.32 \mathrm{E}+7$

$1130 \quad$ G2 $=276$

$1140 \mathrm{M} 2=58.45$

1150 R2 $=2.163$

$1160 \mathrm{Rl}=0.99707$

$1170 \mathrm{Ml}=18.0152$

$1180 \mathrm{~K} 2=0.0021452144$

$1190 \quad \mathrm{~T}=0$

1200 REM CALCULATION OF INITIAL CONCENTRATION X2

$1210 \mathrm{~V} 3=3.14159265359 * F * D^{\wedge} 3 / 6$

$1220 \mathrm{C}=\mathrm{L} 0 * 3 * \mathrm{R} 2 / \mathrm{V} 3$

1230 R3 $=1.0003+0.69941 * C-0.26766 * C^{\wedge} 2+0.24368 * C^{\wedge} 3$

$1240 \times 2=(C * M 1 / R 3) /(M 2+C * M 1 / R 3-C * M 2 / R 3)$

1241 REM CALCULATION OF AMBIENT PRESSURE $P$

1242 REM MAY BE USED FOR HYDRATION ONLY

$1250 \mathrm{Al}=1.13-4.281 * \times 2+5.1711 * \times 2 \wedge 2-2.021 * \times 2 \wedge 3$

1260 IF $X 2>0.097$ THEN 1280

$1270 \mathrm{Al}=0.99936-1.70695 * \times 2-6.50298 * \times 2 \wedge 2-12.35286 * \times 2 \wedge 3$

$1280 \mathrm{P}=\mathrm{Al} * \mathrm{PO}$

$1285 P=P * E X P(4 * E * M 1 / D / R 3 / R / T 1)$

$1290 \mathrm{H}=\mathrm{P} / \mathrm{P} 0 * 100$

1291 REM CALCULATION OF SPHERICAL CAP DIAMETER

$1300 \mathrm{D}=1.5 * \mathrm{~L} 0$

$1310 \mathrm{Vl}=3.14159265359 * F * D^{\wedge} 3 / 6$

$1320 \mathrm{~F} 7=\mathrm{R} 1 * \mathrm{M} 2 / 9 / \mathrm{R} 2 / \mathrm{MI}$

$1330 \mathrm{~L}=((\mathrm{L} 0 \wedge 3-\mathrm{V} l * \mathrm{~F} 7) /(1-\mathrm{F} 7))^{\wedge}(1 / 3)$

$1370 \mathrm{M}=2.9934 \mathrm{E}-23$ 
Table XI continued

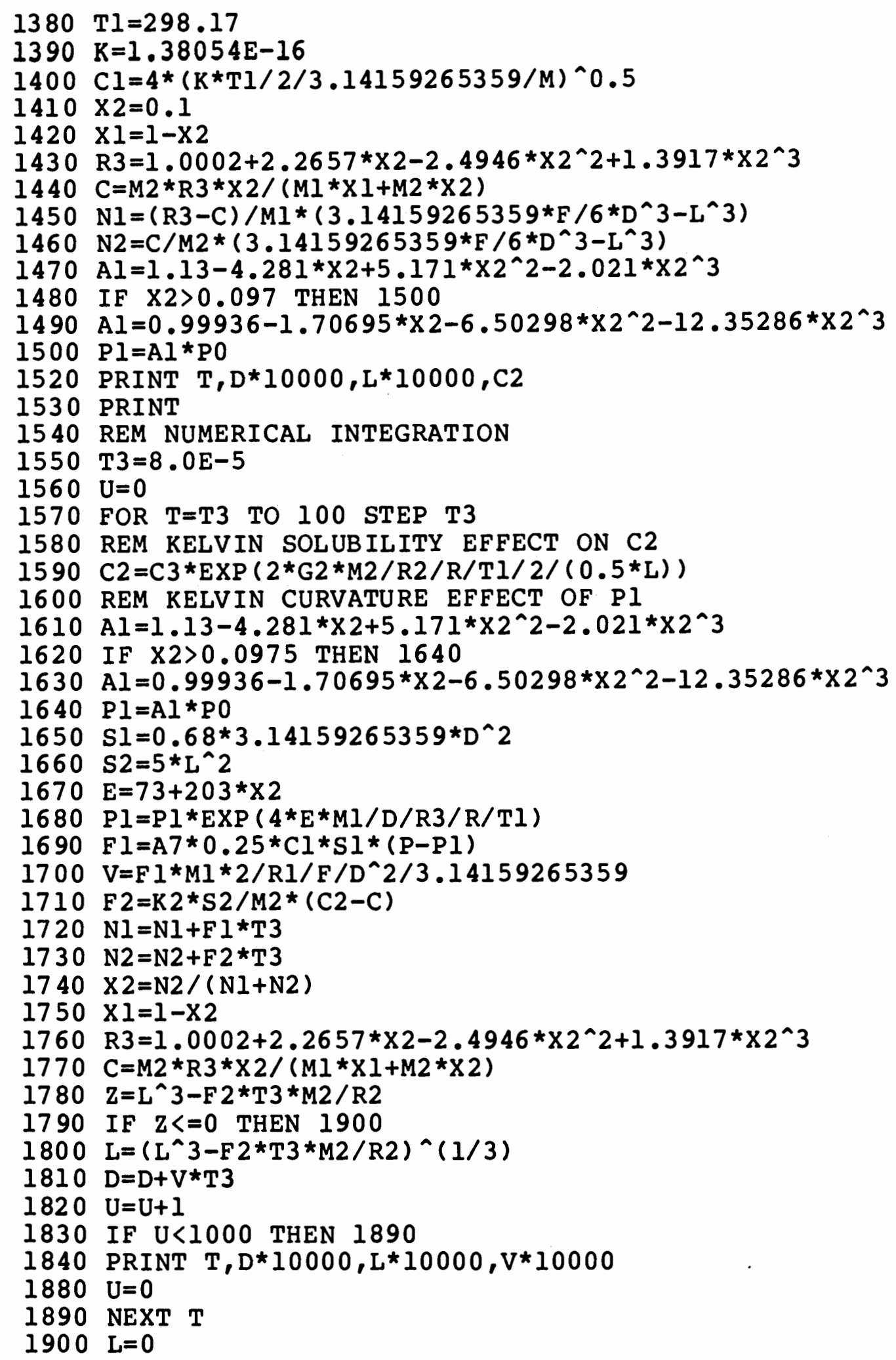


Table XI continued

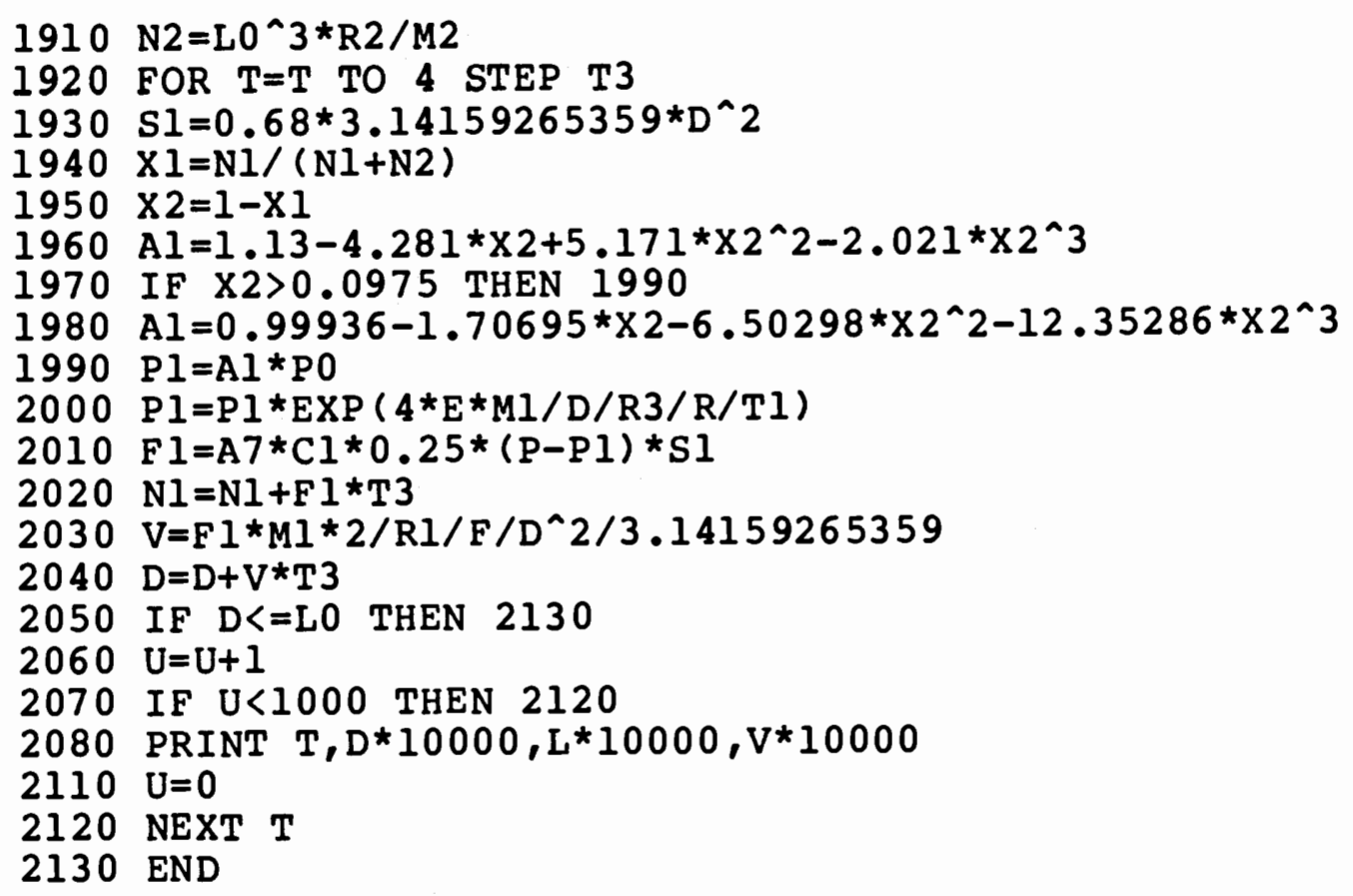


c3 $=0.3179 \mathrm{~g} / \mathrm{cm}^{3}$ (calculated from the vapor

pressure of a saturated sodium chloride

solution (38))

$\mathrm{C}=$ concentration of sodium chloride in solution at any

given time $T$

$\mathrm{Cl}=\overline{\mathrm{C}}=$ relative speed of the water molecule

$\mathrm{Cl}=\overline{\mathrm{C}}=4 \sqrt{\mathrm{K}(\mathrm{Tl}) / 2 \mathrm{PI} M}$

$K=$ Boltzman's constant $K=1.38054 \times 10^{-16} \mathrm{erg} / \mathrm{K}$

$\mathrm{Tl}$ absolute temperature in ${ }^{\circ} \mathrm{K}$

$M=$ mass of a single water molecule, $M=2.9934 \times 10^{-23} \mathrm{~g}$

$A l=a c t i v i t y$ of water: for less than saturated

concentrations a curve was fit to Robinson

and Stokes (38) activity data:

$\mathrm{Al}=0.99936-1.70695 * \times 2-6.50298 * \times 2 \wedge 2-12.35286 * \times 2 \wedge 3$

for supersaturated sodium chloride solutions the cubic spline fit (Chapter III) was used:

$\mathrm{Al}=1.13-4.281 * \times 2+5.1711 * \times 2 \wedge 2-2.021 * \times 2 \wedge 3$

$\mathrm{Xl}=$ mole fraction of water

$\mathrm{X} 2=$ mole fraction of sodium chloride

$\mathrm{PO}=$ pressure of pure water vapor at the experimental

temperature $\mathrm{Tl}$

$\mathrm{P}=\mathrm{ambient}$ vapor pressure, $\mathrm{P}=(\mathrm{H} / 100) \mathrm{PO}$

$\mathrm{H}=$ percent relative humidity

$\mathrm{Pl}=$ water vapor pressure above the droplet, $\mathrm{Pl}=(\mathrm{Al}) \mathrm{PO}$

R3=density of the solution. The values for R3 at any given mole fraction of $\mathrm{NaCl}$ in solution were found by fitting 
a polynomial to the plot of International Critical Tables (40) values for dinsity. The resultant equations are-Density vs. mole fraction $R 3=1.0002+2.2657 * X 2-2.4946 * \times 2 \wedge 2+1.3917 * \times 2 \wedge 3$

Density vs. concentration $R 3+1.0003+0.69941 * C-0.26766 * C^{\wedge} 2+0.24368 * C^{\wedge} 3$

Fa factor used in calculating the droplet volume to account for the fact that the droplet sits on the surface of a grid $F=0.758$ (34)

$R=$ gas constant $R=8.32 \times 10^{7} \mathrm{erg} / \mathrm{K}$-mole G2=surface energy of sodium chloride $\mathrm{G} 2=276 \mathrm{ergs} / \mathrm{cm}^{2}(9)$ R2=density of sodium chloride R2=2.163 $\mathrm{g} / \mathrm{cm}^{3}$ (39) $\mathrm{Rl}=$ density of water at $25^{\circ} \mathrm{C} \mathrm{Rl}=0.99707 \mathrm{~g} / \mathrm{cm}^{3}$ (39) T3=step size for the numerical integration $E=$ surface energy in units of dynes $/ \mathrm{cm}^{2}$ The values for $E$ at any given mole fraction of $\mathrm{NaCl}$ in solution were found by fitting a line to the plot of Adamson's (23) values for $E$ versus $X 2$. In this manner the relationship $E=73+203 * \times 2$ was obtained. $V=$ the change in droplet diameter with time $\mathrm{NI}=$ number of moles of water in solution at any time $\mathrm{T}$ $\mathrm{N} 2$ =number of moles of $\mathrm{NaCl}$ in solution at any tine $\mathrm{T}$ $\mathrm{T}=\mathrm{time}$

C2=concentration of a saturated sodium chloride solution after Kelvin considerations As described in the text of this thesis, the flux of 
salt in moles per second was determined to be $F 2=(1 / M 2)(K 2)(S 2)(C 2-C)$. Likewise, the flux of water in moles per second was determined to be $\mathrm{Fl}=0.25 * \mathrm{~A} 7{ }^{*} \mathrm{Cl}{ }^{*} \mathrm{Sl} *(\mathrm{P}-\mathrm{Pl})$. Both the salt and the water fluxes are defined relative to the salt solution: salt or water leaving the salt solution is defined as a negative flux. These simultaneous differential equations describe the kinetics of the sodium chloride hydration. Since an analytical solution of these simultaneous differential equations could not be found by simple analytical tehniques this program (Table $\times I$ ) was written for numerical integration of these equations.

Thus, given the initial conditions of length of the salt cube in microns, and final diameter of the droplet in microns, the equations can be numerically integrated to determine the fluxes of salt and water. The constants and initial calculations used in the integration are listed in lines 1000 through 1530 of the program and were defined previously in this appendix. Since the diameter of the droplet at some time $T$ is the experimentally measured parameter, not the flux of water in moles per second the following calculation was made: Since $F l=d(\#$ moles of water)/dT

$$
(F 1)(M 1)\left(\frac{1}{R 1}\right)=\frac{d V}{d T} \quad \text { However, } V=\frac{\pi}{6} F D^{3}
$$


$\frac{d V}{d T}=\frac{\pi}{2} F D^{2} \frac{d D}{d T} \quad$ or, $F 1\left(\frac{M l}{R 1}\right)=\frac{\pi}{2} F D^{2} \frac{d D}{d T}$

Therefore, $\frac{d D}{d T}=F 1\left(\frac{M 1}{R 1}\right)\left(\frac{2}{\pi F D^{2}}\right)$ and $D=D+\frac{d D}{d T}(d T)$. Thus, the diameter of the droplet at a given time $I$ is determined.

Two modifications in this program are the inclusion of the Kelvin solubility effect and the inclusion of the Kelvin curvature effect. These effects act as an additional driving force for the hydration or dehydration process. Line 1590 calculates the new equilibrium saturated concentration, C2, considering the Kelvin solubitity effect. This directly affects the flux of salt through the concentration gradient term, $\mathrm{C} 2-\mathrm{C}$, in the flux equation. Likewise, lines 1610 through 1680 calculate the new equilibrium pressure over the droplet, Pl, considering the Kelvin curvature effect. This in turn directly affects the flux of water through the pressure gradient term, $\mathrm{P}-\mathrm{Pl}$, in the flux equation.

Once the salt cube has totally dissolved only the flux of water changes the diameter of the droplet. Addition of water to the droplet now causes dilution and reduced vapor pressure lowering due to the lower solute concentration. The equation for the flux of water is integrated and the new droplet diameter calculated as 
previously described. Lines 1900 through 2130 describe the kinetics of hydration when the salt cube is completely dissolved. 